\title{
The use of a proficiency-based clinical tool in the evaluation of clinical knowledge and skills in the athletic training setting
}

\author{
Shannon L. Baldwin \\ West Virginia University
}

Follow this and additional works at: https://researchrepository.wvu.edu/etd

\section{Recommended Citation}

Baldwin, Shannon L., "The use of a proficiency-based clinical tool in the evaluation of clinical knowledge and skills in the athletic training setting" (2010). Graduate Theses, Dissertations, and Problem Reports. 4562.

https://researchrepository.wvu.edu/etd/4562

This Thesis is protected by copyright and/or related rights. It has been brought to you by the The Research Repository @ WVU with permission from the rights-holder(s). You are free to use this Thesis in any way that is permitted by the copyright and related rights legislation that applies to your use. For other uses you must obtain permission from the rights-holder(s) directly, unless additional rights are indicated by a Creative Commons license in the record and/ or on the work itself. This Thesis has been accepted for inclusion in WVU Graduate Theses, Dissertations, and Problem Reports collection by an authorized administrator of The Research Repository @ WVU. For more information, please contact researchrepository@mail.wvu.edu. 
The Use of a Proficiency-Based Clinical Tool in the Evaluation of Clinical Knowledge and Skills in the Athletic Training Setting

Shannon L. Baldwin, ATC, NCSF-CPT

Thesis submitted to the College of Physical Activity and Sport Sciences

at West Virginia University in partial requirement for fulfillment of the degree of

Master of Science

In

Athletic Training

Michelle A. Sandrey, PhD, ATC, Chair

Sean Bulger, Ed.D.

Allison Hetrick, M.Ed., ATC, CSCS

Division of Sport Sciences

Morgantown, WV

2010

Key words: clinical education, athletic training proficiencies, athletic training competencies, learning over time, board of certification examination 


\begin{abstract}
The use of a Proficiency-Based Clinical Tool in the Evaluation of Clinical Knowledge and Skills in the Athletic Training Setting
\end{abstract}

\title{
Shannon L. Baldwin, ATC, NCSF-CPT
}

Context: Athletic training clinical education has changed significantly since the Commission on Accreditation of Athletic Training Education (CAATE) became the accrediting body for the profession. One of the changes is to require proficiency in both didactic knowledge and clinical performance through evaluation. Clinical education studies are evident and methods of teaching and learning are explored frequently, however little is known about the connection of athletic training students' didactic performance and clinical proficiency competencies with on the field experiences. Objective: The purpose of this study was to create a clinical proficiency evaluation tool as a means to evaluate an athletic training student's clinical skills. Design: The design of this study was a correlation study to note the relationship between GPAs, clinical performance evaluation grades, proficiency grades and the score obtained on the clinical proficiency evaluation tool. Setting: One Division I Mid-Atlantic University with a CAATE-accredited undergraduate athletic training program. Participants: This study included fifteen senior undergraduate athletic training students (6 males and 9 females) with a mean age of $22.5 \pm 1.5$ years. This was a sample of convenience based on availability. Participants included in this study were required to be in their third year in the athletic training program and in good standing in order to graduate at the end of their final semester. The individuals had successfully completed all sophomore, junior, and first semester senior course and proficiency work with a minimum of "proficient" scores. Exclusion criteria included senior students in any other curriculum other than athletic training, individuals in the athletic training program but not in their third year, and individuals who had not scored at least "proficient" in all the proficiencies through the Fall semester of 2009. Intervention: Senior athletic training students were asked to participate in this study, and upon agreement were required to fill out the necessary informed consent paperwork and FERPA forms giving the examiner permission to access their individual scholastic files since acceptance into the athletic training education program through the fall 2009 semester. The students completed the clinical proficiency evaluation tool, which is based upon video scenarios within the established clinical proficiency and competency requirements of the athletic training education program. The tool consists of pictures, questions, situations, and video scenarios that students could experience in the athletic training setting. While viewing the tool, the students completed a 50 item multiple choice test. Upon completion of the examination, answer sheets were collected, and results were recorded. Main Outcome Measures: Based on the results, athletic training students' clinical site grades will correlate highly with the grades obtained from the clinical proficiency evaluation tool, and athletic training students' clinical site grades will improve over the course of each semester. Results: From the possible 16 senior students athletic training students, 15 individuals $(\mathrm{n}=15)$ submitted the required material for a participation rate of $93.75 \%$. The mean GPA was $3.40 \pm .33$. As sophomore students, the mean score for their clinical evaluation grades is $90.2 \%$ $\pm 3.1 \%$. As juniors, the mean clinical evaluation grade is $92.7 \% \pm 4.5 \%$, and as seniors, the mean clinical evaluation grade is $91.4 \% \pm 5.7 \%$. Clinical proficiency score results showed a mean of $88.2 \% \pm 3.0 \%$, and ranged from a minimum of $85.0 \%$ and a maximum score of a $93.0 \%$. Results of the clinical proficiency evaluation tool had a mean of $63.1 \% \pm 5.8 \%$, and scores ranged from a minimum of $48 \%$ to a maximum score of $72 \%$. Strong correlational relationships were found between the junior year clinical evaluation grades and GPA $(\mathrm{r}=.639, \mathrm{P}=.010)$, clinical proficiency grades and GPA $(\mathrm{r}=.711, \mathrm{P}=.003)$, as well as clinical proficiency grades and the junior year clinical evaluation grades $(\mathrm{r}=.754, \mathrm{P}=.001)$. Conclusion: This study shows a strong correlation between GPA and clinical performance evaluation grades, and a moderate correlation between proficiency grades and the clinical proficiency evaluation tool. The clinical proficiency evaluation tool may have some areas of correlation and significance in accordance to the grades and scores already being obtained by programs. Information obtained in this study could be used by individual athletic training education programs to evaluate clinical proficiencies near the end of the athletic training student's senior year. 


\section{ACKNOWLEDGEMENTS}

I would like to take this time to thank my family, friends, and fellow colleagues who have been there for guidance and support through this process. Without their assistance and encouragement I do not think I could have completed this component of my education and professional career. A special word of thanks goes out to my father. Without his guidance and professional editing expertise, the creation of the evaluation tool would not have been possible.

I would like to thank Dr. Michelle A. Sandrey for her guidance through this process. It takes a special person to enjoy research, and I couldn't have done it without her help. Thank you, Dr. Sandrey for giving me the opportunity to come to West Virginia University and obtain my masters degree. I would also like to thank the faculty and staff at West Virginia University for allowing me the opportunity to use their students as the focus of this thesis.

I would also like to thank Allison Hetrick and Sean Bulger for their guidance and insight through the entire course of this endeavor. Thank you both for being there for me through the process and for agreeing to be a part of my committee. Words cannot describe how appreciative I am that you've taken time out of your busy schedules to assist with my thesis. Alley, I feel I am an improved athletic trainer because of you. Thank you so much for all your guidance the last two years.

Lastly, I would like to thank John Hauth, Sean Harkcom, Matthew Miltenberger, and Gerard Rozea for instilling in me the professional values and character it takes to be an excellent athletic trainer. My dedication to this profession began in my undergraduate education, and you are the ones who encouraged me to continue. You are also the individuals that gave me the inspiration to be in this field, to succeed in graduate school, and to continue to advance the profession of athletic training. Thank you all very much. 


\section{TABLE OF CONTENTS}

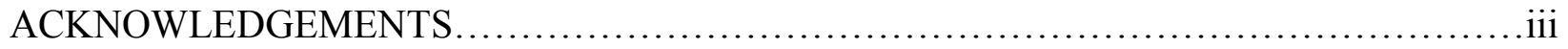

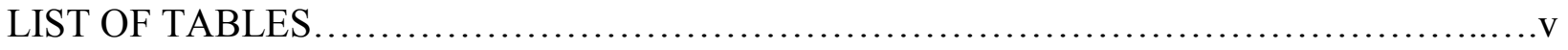

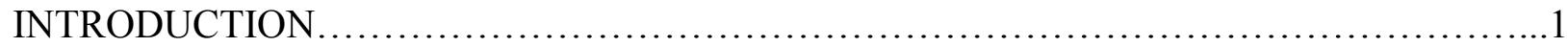

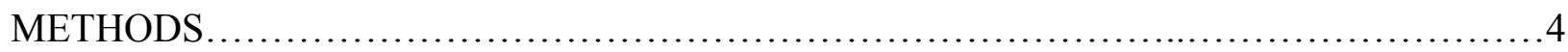

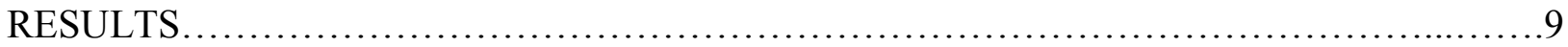

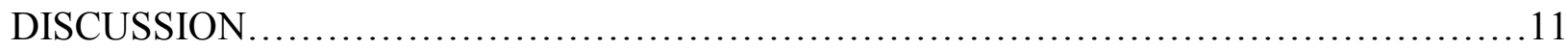

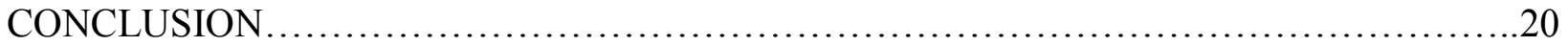

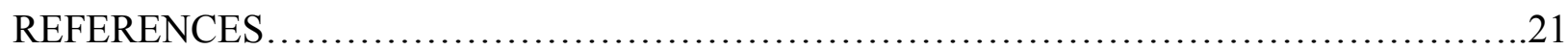

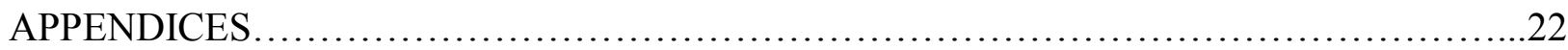

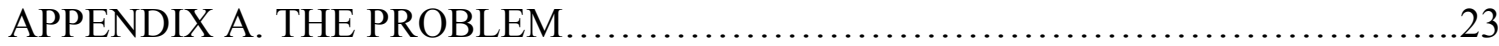

APPENDIX B. LITERATURE REVIEW ...........................................30

APPENDIX C. ADDITIONAL METHODS ......................................5

APPENDIX D. ADDITIONAL RESULTS ........................................ 80

APPENDIX E. RECOMMENDATIONS FOR FUTURE RESEARCH.................82

ADDITIONAL REFERENCES........................................................ 83 


\section{LIST OF TABLES}

Table Page

B1. Twelve Educational Domains.............................................. 40

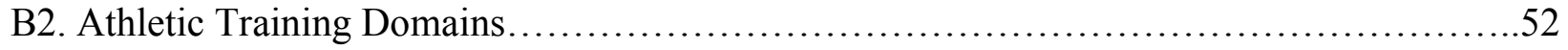

B3. Athletic Training Domains and \% of Questions on Exam.............................52

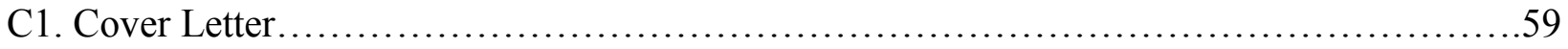

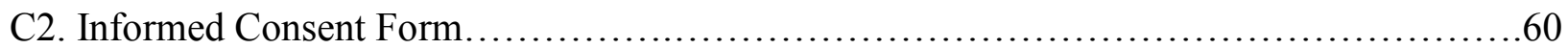

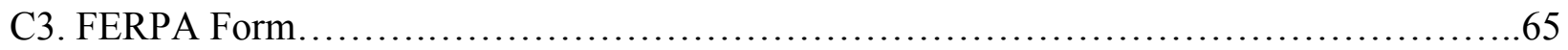

C4. Clinical Proficiency Evaluation Tool............................................66

D1. Descriptive Statistics- Clinical Evaluation.................................... 80

D2. Clinical Evaluation Correlations....................................................... 81 


\section{INTRODUCTION}

In recent years, athletic training education reform has become evident. The National Athletic Trainers' Association (NATA), through the work of the Education Council, revised the Athletic Training Educational Competencies, and the Commission on Accreditation of Allied Health Education Programs (CAAHEP) revised the Standards and Guidelines. ${ }^{1}$ Further changes also occurred in 2006, when CAAHEP no longer accredited athletic training education programs and the Commission on Accreditation of Athletic Training Education (CAATE) became recognized as the independent specialized accreditor. These changes, updates, and reforms placed further emphasis on the importance of clinical education in the athletic training setting.

Athletic training clinical education can be described as the portion of the athletic training student's (ATS) professional preparation that involves the formal acquisition, practice, and evaluation of clinical proficiencies through classroom, laboratory, and clinical experiences in medical care environments. ${ }^{2}$ This formalized education encompasses a relationship between a clinical instructor and student in order to facilitate and integrate athletic training knowledge and skill. Clinical education is the focus among current research; however classroom knowledge and clinical experience in the field are very separate and imperative parts of athletic training education. With the recent changes in clinical education programs as well as changes in the format of the BOC examination, it is clear that changes in the evaluation of clinical education should also be discussed and reform considered as well.

The fourth edition of the Athletic Training Educational Competencies contains the clinical proficiencies for effective preparation of the entry-level athletic trainer. ${ }^{3,4}$ Proficient is defined in the fourth edition as "performing with expert correctness and facility." 3,4 The clinical proficiencies represent "a listing of the student's clinical training before entering the profession" 
and guide group decision making and skill integration. ${ }^{3,4}$ The proficiencies should be a measure of real-life application. ${ }^{3,4}$ The successful development of clinical proficiencies must represent a significant focus of the student's clinical experience and the proficiencies must be organized in such a way that faculty and staff in an athletic training education program (ATEP) can evaluate and monitor student progress over time. ${ }^{3,4,5}$

The primary goal of clinical education is to aid in the acquisition, development, and mastery of clinical proficiencies. ${ }^{6}$ It is important that clinical proficiencies be evaluated similar to what is experienced in the athletic training setting. Conversely, the athletic training clinical proficiencies must be evaluated in a realistic fashion. Presently, quality education markers, or proficiencies, have become a means of standardization of the many skills athletic trainers should acquire in order to be able to sit for the Board of Certification (BOC) examination. The BOC establishes the standards for the practice of athletic training, and is the only accredited certifying body for athletic trainers in the United States. The entry-level certification examination is a computerized examination that is designed to establish standards for entry into the athletic training profession. Although a certified athletic trainer is thought to be competent upon passing the BOC examination, current testing methods do not necessarily evaluate clinical proficiencies. ${ }^{3}$ Accurately assessing students' clinical skills is a key issue for health profession educators. Student clinicians must perform the skills correctly and safely on real patients before they can begin entry-level practice. Therefore, athletic training clinical proficiencies should be a measure of real-life application. ${ }^{7}$

Little research has been conducted on the creation of a proficiency tool within the field of athletic training. Many institutions have their own way of grading and assessing their students, and no one method of widely assessing student performance on proficiency skills has been 
developed. Creating an instrument that will allow program directors to measure proficiency knowledge and skills near the end of the semester year is needed to determine outcomes. Assessment systems should also work seamlessly with, and be incorporated into curriculum design to avoid excessive amounts of effort and time. .,9,10 $^{8}$

The profession of athletic training requires proficiency in both didactic knowledge and clinical performance. Most approved clinical instructors use simulations to evaluate clinical proficiencies, but these simulations may have questionable quality for real-life application. Clinical education studies are evident and methods of teaching and learning are explored frequently, however little is known about the connection with athletic training students' didactic performance and clinical proficiency competencies with on-the-field experiences. Based on the current athletic training clinical literature, the time is now to create a proficiency evaluation tool to objectively evaluate the knowledge obtained throughout an athletic training students' time in the athletic training program. Therefore, the purpose of this study is to create a clinical proficiency evaluation tool which can evaluate an athletic training student's required proficiency and clinical skills. 


\section{METHODS}

Design

The design of this study was a correlational study to note the relationship between athletic training students' GPA's, clinical performance evaluation grades, proficiency grades, and the score obtained on the clinical proficiency evaluation tool. The evaluation tool will include scenarios, pictures, situations, and questions directly related to the already established clinical proficiencies. The score from the tool was compared to students' GPAs and clinical placement evaluation grades to determine if a correlation exists.

Participants

This study used a sample of convenience by including senior undergraduate athletic training students from one Division I Mid-Atlantic University. All students that met the inclusion criteria were asked to participate in this study. In order to be considered for the study, the students were required to be in their third year in the athletic training program and in good standing in order to graduate at the end of their final semester. These individuals needed to successfully complete all sophomore, junior, and first semester senior course and proficiency work with either a mastery or proficient score. A proficient score is a category which equates the student's performance level to an $85 \%$, while a mastery score indicates that the student performed at an excellent level, with a score of $100 \%$. The proficiency topics are given to students each semester, and are on topics the students covered the previous semester, which attempts to incorporate learning over time. These proficiencies are evaluated on an individual basis with an ACI. Exclusion criteria included senior students in any other curriculum other than athletic training, individuals in the athletic training program but not in their third year, and 
individuals who had not scored at least proficient in all the proficiencies up through the Fall semester of 2009.

There were 16 total students asked to participate in this study. After the initial gathering and paperwork collection, all 16 individuals submitted full release of their academic records. On the day of the exam, however, one individual took the exam but did not turn in an answer sheet as responses on the answer sheet were not in order. Therefore, from the possible 16 senior students athletic training students at this Division I undergraduate institution, 15 individuals $(\mathrm{n}=15)$ submitted a usable clinical evaluation tool answer sheet for a participation rate of $93.75 \%$. The final sample included 6 males and 9 females with a mean age of $22.5 \pm 1.5$ years. This study was approved by the Office of Research Compliance at the institution. Instrumentation

A clinical proficiency evaluation tool was created according to the already established clinical proficiency and competency requirements of an undergraduate CAATE accredited athletic training education program from one Division I Mid-Atlantic University. The clinical proficiency evaluation tool was derived from pictures, questions, situations and scenarios related to real life experiences in the athletic training setting. Present proficiency topics that the participants may be held accountable for included proficiencies that were tested throughout each semester as an athletic training student. As a sophomore student in the first semester, proficiencies consisted of crutch fitting, nutrition, wound care and lifting/spotting techniques. The second semester in the student's sophomore year included proficiencies that evaluated lumbar and thoracic spine assessment, knee assessment, foot/toes/ankle/lower leg assessment, and thigh/hip/pelvis/sacroiliac joint assessment. As a first semester junior, the number of proficiencies increased and included mostly evaluation techniques and emergency procedures. 
Assessment for ribs/abdomen/thorax, cervical spine, elbow/forearm, head/face and temporomandibular joint, shoulder/upper arm, and wrist/hand/thumb were included. Emergency procedures, environmental precautions, and protective equipment and custom devices were also assessed. Proficiencies in the second semester of the student's junior year were more modality and rehabilitation related and included electrical-stimulation modalities, infrared modalities, mechanical modalities, massage, ultrasound, lower extremity rehabilitation, and lumbar spine rehabilitation. In the student's final year in the athletic training program, proficiencies in the first semester were related to rehabilitation and fitness and included cervical spine rehabilitation, fitness program design, and upper extremity rehabilitation. The final semester proficiencies were medically and motivational related and consisted of eating disorders, general medical assessment, mental health referral, and motivational techniques.

The Clinical Proficiency Evaluation Tool is a 50-question multiple choice examination with 6 possible responses per question. The video is 50 minutes in length, and contains video taken from actual situations that had been recorded on tape. The multiple-choice questions were presented as they would appear on the Board of Certification examination and similar to questions that could be asked by ACIs during clinical proficiency assessment. To determine what should be included in the content of the tool, faculty and staff members at a Division I MidAtlantic University were surveyed through an email questionnaire as to what they felt were the most important proficiency topics from each level of student in the program. The faculty's responses were tallied, and the most important topics were given more emphasis within the writing of the questionnaire.

Topics that faculty members considered most important were emergency situations, cspine evaluations, splinting techniques, heat illnesses, nutrition, and upper and lower orthopedic 
evaluation. In writing the questions, topics that faculty and staff recommended were followed as closely as possible. Of the 50 questions, 16 dealt with emergency situations, 5 with c-spine evaluation, 2 related to splinting, 5 related to nutrition and eating disorders, 3 dealt directly with heat illness, 3 related to upper extremity evaluation, and 13 questions that dealt with lower extremity evaluation.

A psychometric expert evaluated the tool for face and content validity. Several drafts of the examination format were created and revisions were completed following feedback from the pilot study and psychometric expert before the final draft of the clinical proficiency evaluation tool was created. The pilot study consisted of faculty, staff, and graduate assistants reviewing the DVD for clarity. Before using the tool for data collection, members of the faculty and staff at a Division I Mid-Atlantic University reviewed the tool again to provide additional feedback. Procedures

The Office of Research Compliance was responsible for approving this study. Upon IRB approval, the sixteen senior undergraduate students from one Division I Mid-Atlantic University were asked to participate. They were provided a cover letter (Table C1) and informed of the format and purpose of this study. This occurred 1-2 weeks before the clinical proficiency examination tool was administered. If interested, and if the students met the inclusion criteria, necessary informed consent paperwork (Table C2) was completed. Specifically, students filled out a one-time-use FERPA form (Table C3) giving the examiner permission to access individual scholastic files since acceptance into the athletic training education program through the fall 2009 semester. Students were asked to give permission individually for their personal information (GPAs, clinical performance evaluation grades, proficiency grades, and the clinical proficiency evaluation tool grade) to be released. 
The students were given the examination one time by the undergraduate program director in accordance with practicum classes in March. Brief instructions were given at the beginning of the tool, and a sample problem was presented on the screen. After that, the proficiency evaluation tool video began. Each question and all answers were presented verbally and in written format on the video. The students were cued as to the remaining time to answer each question. This was depicted with green, yellow, and red lights at the bottom of the screen. After the questions and answers were read aloud, students had 15 seconds to answer the question. Upon completion of the examination, students were asked to place answer sheets in an envelope in front of the room. Test results were obtained through hand grading of the exam. The grading was completed by subtracting missed responses from the total possible responses. These results, once tallied, were recorded on a Universal Serial Bus (USB) drive that was kept in a locked drawer. The student's GPA's, clinical performance evaluation grades and proficiency grades were also recorded to the USB. The information gathered was placed into an Excel spreadsheet for future analysis using Statistical Package for the Social Sciences 16.0 (Chigaco, Illinois), to analyze the data.

\section{Data Analysis}

The data collected included senior athletic training student's GPA, clinical performance evaluation grades, proficiency grades for all three years in the program, and the grade obtained from the clinical proficiency evaluation tool. The GPA is the student's cumulative GPA after the fall semester of their third year in the athletic training program.

The clinical performance evaluation grade consisted of an average of the clinical site rotation grades for each semester as determined by the student's clinical placement ACI. The 
students' semester clinical performance grades were recorded and averaged for one score for each of the three years within the athletic training program.

The student's proficiency grades were gathered from the student's sophomore, junior, and senior years, and the scores were averaged for one cumulative proficiency grade for each year in the program. Students obtained scores of either "mastery" or "proficient" according to performance on the completed proficiencies. A "mastery" score is equivalent to a $100 \%$, and a “proficient" score was counted as $85 \%$. All students were required to test at the proficient level or above in order to pass the proficiency and each proficiency is administered to test learning over time.

The clinical proficiency evaluation tool was graded by hand by subtracting missed answers from the total possible responses. The tool consisted of 9 different scenarios, with a variable number of multiple choice questions pertaining to the situation. The total possible points for the 50 multiple response questions on the clinical proficiency evaluation tool was 141 . The total numbers of points deducted were subtracted from the 141 points possible. To obtain the percentage score for the tool, the total points obtained were divided by the total points possible. This yielded a percentage grade, and through statistical analysis was explained as a percentage of the total score.

\section{Statistical Analysis}

The student's GPAs, competency and clinical performance evaluation grades, proficiency grades, and clinical proficiency evaluation tool grades were evaluated for trends and patterns. Results of the clinical proficiency evaluation tool, GPA's, and clinical performance evaluation grades were analyzed using descriptive statistics including means, standard deviations, and Pearson Product Moment Correlation coefficients. The $\mathrm{P}$ value for analysis was $\mathrm{P}=0.05$. 
Correlations were defined with a weak correlation indicated by an $\mathrm{r}$ value $<.3$, a moderate correlation indicated by an $\mathrm{r}$ value between $.3-.6$, and strong correlations will be indicated by $\mathrm{r}$ values $>.6$ respectively. All data was analyzed using SPSS version 16.0 for Windows. (SPSS Inc. Chicago, IL.)

\section{RESULTS}

Of the 15 participants, the mean GPA was $3.40 \pm .33$, with a minimum GPA of 2.82 and a maximum GPA of 3.99, respectively. It is interesting to note the differences of each grade's clinical evaluation scores. As sophomore students, the mean score for their clinical evaluation grades is $90.2 \% \pm 3.1 \%$. As juniors, the mean clinical evaluation grade is $92.7 \% \pm 4.5 \%$, and as seniors, the mean clinical evaluation grade is $91.4 \% \pm 5.7 \%$. Clinical proficiency score results of the combined 3 years showed a mean of $88.2 \% \pm 3.0 \%$, and ranged from a minimum of $85.0 \%$ to a maximum score of 93.0\%. Results of the Clinical Proficiency Evaluation Tool had a mean of $63.1 \% \pm 5.8 \%$, and scores ranged from a minimum of $48 \%$ to a maximum score of $72 \%$. Their percentage grade scores were calculated by totaling the number of correct responses over the total number of correct responses to the 50 multiple-response questions, which was 141 points. Refer to Table D1 for all mean, standard deviation, and range descriptive statistics.

Strong correlational relationships were found between the junior year clinical evaluation grades and GPA $(\mathrm{r}=.639, \mathrm{P}=.010)$, clinical proficiency grades and GPA $(\mathrm{r}=.711, \mathrm{P}=.003)$, as well as clinical proficiency grades and the junior year clinical evaluation grades $(r=.754$, $\mathrm{P}=.001$ ). Moderate correlational relationships were found between the clinical proficiency evaluation tool and $\operatorname{GPA}(\mathrm{r}=.554, \mathrm{P}=.032)$ as well as between the clinical proficiency evaluation tool and clinical proficiency grades $(\mathrm{r}=.329, \mathrm{P}=.231)$. Refer to Table $\mathrm{D} 2$ for all clinical evaluation correlation data. 


\section{DISCUSSION}

The purpose of this study was to create a performance tool to evaluate an athletic training students' clinical skills. The participants included fifteen senior undergraduate athletic training students in the third year of the athletic training program and in good standing in order to graduate at the end of their final semester. To date, this is the first study to look at a performance tool to evaluate athletic training student's clinical skills in a format similar to the BOC examination.

There were four hypotheses for this study. The first was that athletic training students' clinical performance evaluation grades will improve over the course of each year. This hypothesis was accepted from the student's sophomore to junior year, but was rejected from student's junior to senior years. Second, the athletic training student's overall GPA will correlate strongly with their clinical performance evaluation grades. This was accepted with a strong correlation. Third, the athletic training students' proficiency grades will strongly correlate with the grades obtained from the clinical proficiency evaluation tool, which was rejected with a moderate correlation. Fourth, athletic training student's clinical performance evaluation grades will be a strong correlation with the grades obtained through the clinical proficiency evaluation tool, which was also rejected. It was expected that the clinical proficiency evaluation tool would reflect a strong connection with GPA and other clinical measures, as this tool depicts what has been learned in the clinical setting throughout the three years in the athletic training program. However, only moderate to low correlations existed.

Clinical Proficiency Evaluation Tool

One of the primary goals of clinical education is to aid in the acquisition, development and mastery of clinical proficiencies, which must be evaluated in a realistic fashion. ${ }^{3,6}$ If an 
actual clinical exposure does not occur, then a scenario is used in the evaluation. Often times a scenario is not used and the athletic training student may repeat a memorized plan of action. Furthermore, the clinical proficiency must be repeated until the minimum score of "proficient" is obtained. To evaluate senior athletic training students' proficiency knowledge, the clinical proficiency evaluation tool was created as a culmination of all clinical proficiencies throughout the three years in the athletic training program. The tool that was used in this study was created using real time video clips; a portion of technology similar to what the BOC examination is striving for, but also with an objective technique. The clips and questions included in the tool were topics deemed important and selected by an institution's staff members to ensure the video covered what the staff felt the students should know. In addition, the tool was created in such a way as to foster critical thinking and learning over time.

The clinical proficiency evaluation tool was created in accordance with the proficiencies that are evaluated at one Division I Mid-Atlantic institution. The questions included in the tool were based on situations and scenarios that any athletic trainer from any program may experience despite being specific to the institution. The questions were based on all the proficiency topics from the student's three years in this institution's athletic training program, including specific questions that both academic and clinical ACI's depicted as being most important. These topics included emergency situations, c-spine evaluation, splinting, nutrition/eating disorders, heat illness, as well as upper and lower evaluation.

When looking at the tool, there was at least one question that related to each specific proficiency. Some of the questions and situations presented covered multiple proficiencies at a time. There were 16 questions out of 50 that dealt with emergency situations. To make the emergency situations more realistic to an athletic training setting, evaluation and rehabilitation of 
both upper and lower extremity injuries were also included. To further examine upper and lower extremity injuries, 3 questions related to upper extremity evaluation and 13 lower extremity evaluation questions were added. To evaluate medical emergencies, 5 questions were added for c-spine evaluation, 3 for heat illness, and 2 for splinting. Eating disorders and nutrition questions were combined for a total of 5 questions.

When looking at the results from the individual students' scores, there were two questions that every person in the class got correct, and both these were emergency-related questions. Questions pertaining to emergency situations were where the students in this study scored the best, with the entire class missing the least amount of points. The senior students in this study performed the worst in upper and lower extremity evaluations, as this was where the most number of points were deducted from their total scores.

In the student's sophomore year, they are responsible for taking lower and upper orthopedic evaluation classes in the fall and spring semesters, respectively. It is somewhat surprising that these scores were the lowest of all the topics deemed important, especially since students are supposed to have clinical sites that correspond to both upper and lower-dependent sports. ${ }^{5}$ Additionally, the year in which these upper and lower extremity dominant dependent clinical placements are assigned may also have affected the outcome of those specific tool questions. Furthermore, the upper and lower evaluation proficiencies are not repeated in the student's senior year, as it is assumed there will be more real-life situations available for them to further hone their skills. It is also is interesting that the emergency questions were the ones that the students scored the highest on, especially since some of the scenarios presented were rare events that most athletic training students had not ever had direct field experience. 
The Commission on Accreditation of Athletic Training Education dictates the proficiency topics that are repeated from the year in a subjective testing format to ensure that the students are able to demonstrate learning over time and critical thinking. Critical thinking demands a skillful application of knowledge and experience in making discriminating judgments and evaluations. ${ }^{2}$ The critical thinking skills tested during the clinical proficiency evaluation tool were given in a format that the athletic training students were unfamiliar with from their regular subjective, one topic at a time proficiency tests. This different format could very well be a reason that the exam tool's scores were lower than the rest of the data collected. The tool was given as a comprehensive one-time objective exam, in which the students did not prepare for in any way. This may be another reason for the differences in scores in comparison to the rest of the data that was collected over time.

Athletic training students are accustomed to methods of testing that are supposed to show and test critical thinking. Usually in the classroom, these exams come as memorization tests, while in the field or during proficiency testing, students are given a list of information that needs to be covered and then restate that list to the ACI. These methods, while they are able to give the students a letter grade, are not truly indicative of the actual critical thinking knowledge they have gained. Additionally, proficiency evaluation should be completed using scenarios or actual field situations, however there is no way to know for sure if this is actually being accomplished for every proficiency that is evaluated by the staff. ${ }^{5}$

The proficiencies that the students complete with their ACIs have the potential to show how well these students would handle real-life situations; however this is not necessarily true in every situation. The grading and scoring of proficiency testing at this institution is based on a rubric, and the students are given a copy of what they need to do and say in order to score 
"proficient" or "mastery." Memorizing the list of questions to ask, tests to perform, and the differential diagnoses possible may be enough to master the proficiency skill when tested by the $\mathrm{ACI}$, however this checklist may not be retained when the situation arises in real life on the field.

It is difficult to create a tool to cover all the specifics of each proficiency the students were responsible for. A few questions on each topic cannot come close to covering everything the students know and learned over their time in the classroom and in the field. This tool may not be a great indication of their overall knowledge on the subject matter.

Modifications should be made to this tool before it would actually show true and realistic results in the athletic training setting. First, creating the same style type of test on a more specific topic level might be beneficial. This way instead of a broad overview of each proficiency topic, students would be able to be tested on each proficiency individually, and all areas of the proficiency topic would be covered. Secondly, more specific videos of scenarios could be found or even created as well to depict a greater variety of situations and scenarios that students could see in the field. Using this method of testing would be ideal as well, since each student would be tested on the material in exactly the same way. Students would know how well they did with each proficiency, and could get extra help in the clinical setting with topics they were not as strong with.

Creating one standardizing tool to encompass everything within the field of athletic training is next to impossible, and it takes away from the individuality of each athletic training institution. Every injury in athletics is different, and every situation in the field may be resolved successfully in a number of different ways. However, use of a tool that attempts to cover a wide variety of topics may be a great preparation practice tool for senior students as they prepare to sit 
for the BOC examination. Not only is the BOC examination in a similar format, but it also attempts to cover everything an entry-level athletic trainer should know.

Clinical Evaluation

Clinical education comprises a large portion of professional preparation in athletic training and other allied health care fields, and makes a substantial contribution to the professional preparation of athletic training students. ${ }^{1}$ Athletic training education programs must provide the proper type and amount of clinical supervision in order for athletic training students to obtain appropriate clinical education and to meet Board of Certification requirements.

Overall, the mean scores for clinical performance evaluation grades did not increase over the course of each year. In fact, the results of this study showed that the sample students' junior clinical performance evaluation grades were the best of the three years shown (sophomore 90.2\% $\pm 3.1 \%$, junior $92.7 \% \pm 4.5 \%$, senior $91.4 \% \pm 5.7 \%$ ). There are many reasons why this could be. At this institution, as well as others across the board, ${ }^{5}$ athletic training students' junior year provides them with the most athletic training courses that will be used in the clinical setting. Students in this year of college have the higher-level athletic training courses, the most practical assignments, and even more clinical proficiencies. The last semester of the senior year tends to be more focused on what is next, whether it is entering the work force, going on for more schooling, or taking the BOC examination. Stress levels at this time may be high. ${ }^{5}$ The academic focus is different too at this point in the athletic training program. The athletic training classes senior students take, especially the practicum class, are designed with a direct focus on preparation and practice for taking the Board of Certification examination. ${ }^{5}$

The athletic training student's GPA correlated with the clinical performance evaluation grades especially during the student's junior year. It did so with a strong correlation $(\mathrm{r}=.639$, 
$\mathrm{P}=.010$ ). Athletic training student's junior year performance is most in sync with the overall cumulative GPAs. This is an interesting statistic as well, since again, the student's junior year is the year in which the most important athletic training classes are taken. The sophomore grades for performance evaluation are ranked the lowest in comparison to student's junior and senior years. This is expected because it is the student's first year in the program, and they are provided with work for the upcoming semesters. It is interesting to note that the senior's clinical performance evaluation grades decreased from the junior year statistics. This slight decrease could again include the future post-graduate plans related to passing the BOC examination. The student's senior year is also related to proficiencies covering all three years as they are required to work directly with younger sophomore and junior students on their skills.

Athletic training student's clinical performance evaluation grades had a moderate correlation with the grades obtained through the clinical proficiency evaluation tool. The grading of the evaluation tool was objective, while the semester clinical performance evaluation grades were done by individual approved clinical instructors (ACIs). There is a grading rubric for these evaluations; however, there is no standardizing method as to what injuries the students are presented with in each scenario or how their skills are subjectively evaluated. The subjectivity of these evaluation grades and the objective aspect of the evaluation tool could potentially lead to the differences.

\section{Clinical Implications and Limitations}

The clinical proficiency evaluation tool included the proficiency topics that were rated the highest of importance by certified athletic trainers at this Mid-Atlantic athletic training program. Different programs in different areas may feel levels of importance are different, and 
others may strictly adhere to the Role Delineation Study's suggestions. If this method of testing were to be used as a nation-wide tool, a form of regulation must also be used.

Little research has been conducted on the creation of an assessment tool within the field of athletic training for assessment of proficiencies. However, the development of two assessment tools ${ }^{8,9}$ reported in the literature may provide guidance. The Online Assessment of Athletic Training Education (OAATE) instrument was developed by Carr, and the Standardized Orthopedic Assessment Tool (SOAT) was created by Lafave. ${ }^{8,9}$ Both instruments were developed and created as standardizing tools for education and assessment. Their research and testing methods both concluded that in order for tools such as the one created in this study, they must use the most recent and up to date version of educational competencies. ${ }^{9}$ In order for a tool such as the one created for this study to be useful, it must be created according to national educational standards as well as the standards within each individual athletic training institution. ${ }^{8,9}$ This may be the focus of further research in creating a standardized tool in the assessment of clinical proficiencies.

Actual exposure to real-life situations may be limited by the ACI and the time spent in the athletic training room. Real-life situations that athletic training students may see while they are on the field do happen, however there are many regulations in place that allow for the protection of student athletes that may limit the contact athletic training students have with these individuals. ${ }^{5}$ Athletic training students may not get the opportunity to touch an athlete in any given emergency injury situation since students may only be present at practices and games in the presence of a certified athletic trainer who might take control of any of these situations. Additionally, with the amount of time athletic training students can be in the field ${ }^{5}$ over the course of a week, athletic training students are limited in their exposure. Anything the students 
do beyond 20 hours a week is optional, and students cannot be penalized for not exceeding the minimum amount of hours possible. ${ }^{5}$ Some students only put in their allotted 20 hours a week; and in doing so, might miss out on learning opportunities and the hands on experience that goes on within the clinical setting. Athletic training students, for the most part, are not able to travel with their teams for overnight road trips unless a certified is there also. This again limits the student's ability to make their own decisions independently of a certified athletic trainer, which helps contribute to critical thinking and learning over time.

Participants in this study were limited to the senior students in one Division I MidAtlantic athletic training undergraduate program, and only consisted of 15 participants. A larger sample size, including a larger sample of athletic training programs, would have been ideal. Additionally, the GPA scores that were taken were not strictly athletic training GPAs; they were overall GPAs from all the student's classes. Using athletic training GPAs might have better represented athletic training didactic knowledge. Also, since the tool was only taken once, there might have been a potential for students to score higher on the exam if they had an opportunity to become familiar with the objective testing format combining cumulative critical thinking and learning over time.

In future studies, it may be possible to create proficiency tools for each individual topic covered by each institution. Doing this could help to cover a wider variety of situations and scenarios specific to each proficiency, and also provide a means for evaluating the student objectively. Another option would be to create a yearly comprehensive examination in the same manner to look closely at which skills each athletic training student has truly mastered. These yearly scores could potentially be correlated with the pass/fail rate of the BOC examinations in each individual institution. 


\section{CONCLUSION}

The clinical proficiency evaluation tool, used in this study, had some degree of correlation and significance in relation to the didactic grades and proficiency scores already obtained. Statistical analysis comparing senior athletic training student's GPAs, clinical performance evaluation grades, proficiency grades, and the score from the clinical proficiency evaluation tool show a strong correlation between GPA and clinical performance evaluation grades, and a moderate correlation between proficiency grades and the clinical proficiency evaluation tool. The results from the tool also display that students showed the most success in emergency-related scenarios, as indicated by the scores obtained. The scores from the upper and lower orthopedic evaluation questions were the lowest.

This tool, created also in accordance to the updated Board of Certification Examination format, may be considered a practice aid in student preparation as well. Additionally, information obtained in this study could potentially be used by individual athletic training education programs to evaluate senior student's preparedness for the BOC examination and as an objective tool to evaluate the level of knowledge of proficiencies up to the last semester. Creating modifications to athletic training programs and preparation would not only improve the quality of patient care and patient education, but can also raise the standards for the profession of athletic training. 


\section{REFERENCES}

1. Laurent T, Weidner TG. Clinical-education-setting standards are helpful in the professional preparation of employed, entry-level certified athletic trainers. J Athl Train. 2002;37(4 Supplement): S-248-S-254.

2. Weidner TG, Henning JM. Historical perspective of athletic training clinical education. $J$ Athl Train. 2002;37(4 Supplement): S-222-S-228.

3. Walker SE, Weidner TG, Armstrong KJ. Evaluation of athletic training students' clinical proficiencies. J Athl Train. 2008;43(4):386-395.

4. National Athletic Trainers; Association. Athletic Training Educational Competencies. $4^{\text {th }}$ ed. Dallas, TX: National Athletic Trainers’ Association;2006.

5. Commission on Accreditation of Athletic Training Education clinical education terminology. http:// ://www.nata.org/student/caateterms.htm. Accessed September 4, 2009

6. Cheung MT, Yau KKW. Objective assessment of a surgical trainee. ANZ J Surg. 2002;72(5);325-330.

7. Armstrong KJ, Weidner TG, Walker SE. Athletic training approved clinical instructors' reports of real-time opportunities for evaluation clinical proficiencies. J Athl Train. 2009;44(6):630-638.

8. Lafave MR, Katz L, Donnon T, Butterwick DJ. Initial reliability of the standardized orthopedic assessment tool (SOAT). J Athl Train. 2008;43(5):483-488.

9. Carr WD, Frey BB, Swann E. Development of the online assessment of athletic training education (OAATE) instrument. Athl Train Educ J. 2009;4(2):66-69.

10. Craig DI. Applying brain-based learning principles to athletic training education. Athl Train Educ J. 2007;2:16-20. 
APPENDICES 


\section{APPENDIX A}

\section{THE PROBLEM}

\section{Research Question}

In recent years, athletic training education reform has become evident. The National Athletic Trainers' Association (NATA), through the work of the Education Council, revised the Athletic Training Educational Competencies, and the Commission on Accreditation of Allied Health Education Programs (CAAHEP) revised the Standards and Guidelines. ${ }^{1}$ Further changes also occurred in 2006, when CAAHEP no longer accredited athletic training education programs and the Commission on Accreditation of Athletic Training Education (CAATE) became recognized as the independent specialized accreditor. These changes, updates, and reforms placed further emphasis on the importance of clinical education in the athletic training setting.

Clinical education can be defined as the hands-on experience involving clinicians, students, and patients in a real-life environment. The experiences allow a realistic component to a student's education. The purpose of clinical education is to "provide the student with sufficient opportunity to develop specific competencies pertaining to the health care of the athlete and those involved in physical activity." In addition, evaluation of these competencies is important to provide an academic component to the clinical setting.

The fourth edition of the Athletic Training Educational Competencies contains the clinical proficiencies for effective preparation of the entry-level athletic trainer. ${ }^{3,4}$ Proficient is defined in the fourth edition as "performing with expert correctness and facility." 3,4 The clinical proficiencies represent "a listing of the student's clinical training before entering the profession" and guide group decision making and skill integration. ${ }^{3,4}$ The proficiencies should be a measure of real-life application. ${ }^{3,4}$ The successful development of clinical proficiencies must represent a 
significant focus of the student's clinical experience and the proficiencies must be organized in such a way that faculty and staff in an athletic training education program (ATEP) can evaluate and monitor student progress over time. ${ }^{3,4,5}$

The primary goal of clinical education is to aid in the acquisition, development, and mastery of clinical proficiencies. ${ }^{6}$ It is important that clinical proficiencies be evaluated in manners similar to their applications in real life. Similarly, the athletic training clinical proficiencies must be evaluated in a realistic fashion. Presently, quality education markers, or proficiencies, have become a means of standardization of the many skills athletic trainers should acquire in order to be able to sit for the Board of Certification (BOC) examination. The BOC established the standards for the practice of athletic training, and is the only accredited certifying body for athletic trainers in the United States. The entry-level certification examination is a computerized examination that is designed to establish standards for entry into the athletic training profession. Although a certified athletic trainer is thought to be competent upon passing the BOC examination, current testing methods do not necessarily evaluate clinical proficiencies. ${ }^{3}$

Clinical education is the topic of choice for current research; however classroom knowledge and clinical experience in the field are very separate and imperative parts of athletic training education. With all the recent changes in clinical education programs as well as changes in the format of the BOC examination, it is clear that changes in the evaluation of clinical education should also be discussed and reforms considered as well.

As a senior athletic training student, much of the didactic knowledge has been obtained, tested, and theoretically should have been applied in clinical practice. At one Division I MidAtlantic University, athletic training students receive both classroom and clinical grades from their respective professors and approved clinical instructors (ACI's) each semester. There is no 
connection between actual clinical experience and the work completed in the classroom other than clinical proficiencies and the students' midterm and final clinical evaluations. The proficiency competencies represent learning over time, and the students are evaluated on skills they learned the previous semester. This encourages each student to go back and review past information to be allowed the opportunity to "master" each skill. The midterm and final evaluations are completed by the ACI and determine each student's clinical education performance. What remains in question is the correlation between a student's classroom and clinical performance with regards to each specific skill required for each level of proficiencies. As of now, completion in mastering proficiencies represents $50 \%$ of the final grade for practicum class.

The profession of athletic training requires proficiency in both didactic knowledge and clinical performance. Clinical education standards are often evaluated and methods of teaching and learning are explored frequently, however there is an absence of information that links athletic training students' didactic performance and clinical proficiency competencies with onthe-field experiences.

Therefore, my research questions are:

1. Is there a correlation between a senior athletic training student's athletic training GPA and clinical performance evaluation grades as determined by the institution's ACIs?

2. Are the proficiency competencies a good means for evaluating if an athletic training student can perform in the clinical setting?

3. Does the athletic training students' GPA determine how well they will do on their proficiency standards?

4. Does a visual method of testing an athletic training student on proficiency standards correlate with the student's clinical performance? 
Experimental Hypotheses

1. Athletic training students' clinical performance evaluation grades will improve over the course of each year.

2. Athletic training student's GPA will correlate strongly with their clinical performance evaluation grades.

3. Athletic training students' proficiency grades will strongly correlate with the grades obtained from the clinical proficiency evaluation tool.

4. Athletic training student's clinical performance evaluation grades will correlate highly with the grades obtained through the clinical proficiency evaluation tool.

Assumptions

1. All subjects will answer the video testing questions to the best of their ability.

2. The clinical proficiency evaluation tool will be based directly from the proficiency skills learned throughout the course the athletic training student's undergraduate education.

3. The participants will give permission for GPA records, proficiency scores, and competency and clinical performance evaluation grades to be released.

Delimitations

1. The questions formulated on the clinical proficiency evaluation tool represented material on the proficiency standards of one Division I Mid-Atlantic athletic training undergraduate program.

2. Participants in this study included athletic training senior students from one Division I Mid-Atlantic athletic training undergraduate program.

3. Each clinical setting's ACIs evaluated athletic training students differently in relation to letter grade percentages.

4. The results of this study and the video examination test will not be generalized to other institutions based on each program's individual criteria, testing, and grading methods.

Operational Definitions

1. Allied Health Care Professional- Physician Assistants, physical therapists, registered nurses, doctors of dental surgery, and other health care professionals, recognized by the AMA/AOA as allied health professionals, who are involved in direct patient care and are used in the didactic and clinical education portions of the ATEP. These individuals may or may not hold formal appointments to the instructional faculty. ${ }^{5}$ 
2. Approved Clinical Instructor (ACI)- An appropriately credentialed professional identified and trained by the program CIE to provide instruction and evaluation of the Athletic Training Educational Competencies and/or Clinical Proficiencies. The ACI may not be a current student within the ATEP. $2,5,11,12,16,17,18$.

3. ATEP-Athletic Training Education Program. ${ }^{5}$

4. Athletic Training Student- A student enrolled in the athletic training major or graduate major equivalent. ${ }^{5}$

5. Board of Certification- Determines the standards for the practice of athletic training. The BOC is the only accredited certifying body for Athletic Trainers in the US. The BOC was incorporated in 1989 to provide a certification program for entry-level Athletic Trainers and recertification standards for Certified Athletic Trainers. The entry-level certification program is designed to establish standards for entry into the athletic training profession. ${ }^{16}$

6. Board of Certification Examination- An examination which is set to establish and test standards for entry into the profession of athletic training. ${ }^{16}$

7. Certified Athletic Trainer (ATC)- Works with physicians and other medical personnel, employers, patients, parents, guardians, and athletic personnel in the development and coordination of efficient and responsive health care delivery systems. Athletic trainers are integral members of the health care team in secondary schools, colleges and universities, professional sports programs, sports medicine clinics, corporate/industrial, and other health care settings. 5,16

8. Clinical Education- The application of knowledge and skills learned in didactic and laboratory settings, to actual practice on patients under the supervision of an ACI/CI. ${ }^{2,5}$, $11,16,17,18,19,20,21,22,23$.

9. Clinical Experience- Those clinical education experiences for the Athletic Training Student that involve patient care and the application of athletic training skills under the supervision of a qualified instructor. ${ }^{5}$

10. Clinical Instruction Site- The location in which an ACI or CI interacts with the ATS for clinical experiences. If the site is not in geographical proximity to the ATEP, then there must be annual review and documentation that the remote clinical site meets all educational requirements. ${ }^{5}$

11. Clinical Instructor- An individual identified to provide supervision of athletic training students during their clinical experience. An ACI may be a CI. The ACI may not be a current student within the ATEP. ${ }^{2,5,17,18,21,22,24,25,26,27 .}$ 
12. Clinical Instructor Educator (CIE)- The BOC Certified Athletic Trainer recognized by the institution as the individual responsible for ACI training. If more than one individual is recognized as a CIE for an ATEP, then at least one of those individuals must be a BOC Certified Athletic Trainer. ${ }^{5}$

13. Commission on Accredited Athletic Training Education (CAATE)- The agency responsible for the accreditation of entry-level Athletic Training educational programs. Their purpose is to develop, maintain, and promote appropriate minimum standards of quality of entry level athletic training education programs. ${ }^{5}$

14. Competencies- The education content required of entry-level athletic training programs. These competencies should be used to develop the curriculum and educational experiences of a student enrolled in CAATE-accredited entry-level athletic training education program. ${ }^{5}$

15. Critical Thinking- Learning that occurs as a result of working toward a conclusion, rather than accepting the unchallenged and finished product of someone else's conclusion. It demands a skillful application of knowledge and experience in making discriminating judgments and evaluations. $2,11,24,25,28,29,30,31,32,33,34,35,36,37,38$

16. Learning Over Time (mastery of skills)- The process by which professional knowledge and skills are learned and evaluated. This process involves the initial formal instruction and evaluation of that knowledge and skill, followed by a time of sufficient length to allow for practice and internalization of the information/skill, and then a subsequent reevaluation of that information/skill in a clinical (actual or simulated) setting. $5,28,33$

17. Proficiencies- The entry-level athletic training clinical proficiencies define the common set of skills that entry-level athletic trainers should possess and redefine the structure of clinical education from a quantitative approach to an outcome-based qualitative system. ${ }^{5}$

18. Program Director- The full-time faculty member of the host institution and a BOC Certified Athletic Trainer responsible for the administration and implementation of the ATEP. ${ }^{5,27,33}$

19. Standards for the Accreditation of Entry Level Educational Programs for the Athletic Trainer (Standards)- Used to prepare entry-level athletic trainers for the development, evaluation, analysis, and maintenance of ATEPs. ${ }^{5}$

\section{Limitations}

1. Participants in this study were limited to the senior students in one Division I MidAtlantic athletic training undergraduate program.

2. Generalizations of findings to other settings- An external validity threat where the findings of the participants are generalized towards a target population. 
3. Selection of participants- An external validity threat based on the choice of participants as a random group or an experimentally accessible group.

4. Testing site- All participations are to take the video examination in one location on one testing day in accordance with their classroom and clinical schedules. This may or may not ensure a quiet atmosphere.

5. Test anxiety- A psychological condition in which a person experiences distress before, during, or after an exam or other assessment to such an extent that this anxiety causes poor performance or interferes with normal learning.

6. Hawthorne effect- The phenomenon that research subjects change their behavior simply because they know that they are being studied.

Significance of the Study

Determining how students can benefit from the combination of clinical experience, classroom education, and proficiency testing is the primary focus of this study. Integration of all aspects is important to the performance of a certified athletic trainer in the field, and finding a connection between all parts could help athletic training education programs develop better clinical evaluation tools for the student's overall performance. This, could, in turn, help to determine how each student individually would perform in the field, in addition to mastering proficiencies and passing an entry-level BOC examination.

The information obtained in this study could potentially be used by individual athletic training education programs to evaluate and revise current standards by placing the focus on areas of individual and program weakness. By disseminating findings through conferences, workshops, presentations, and publications, athletic training education programs can benefit by doing what is necessary to properly train athletic training students for entry-level clinical positions upon graduation. These modifications in the athletic training education programs will not only improve the quality of patient care and patient education, but can also raise the standards for the profession of athletic training. 


\section{APPENDIX B}

\section{LITERATURE REVIEW}

Introduction

Athletic training education programs first appeared in the 1950's, and drastic changes have been made since that point in time. The first curriculum model of athletic training education appeared in 1959, and in 1969 the recognition of approved undergraduate programs began. As the number of athletic training education programs increased, so did the number of athletic training students. In the late 1970's, early 1980's, a formalized list of behavioral objectives, called competencies, was created. In the 1980's as well, the NATA board of directors required an approved athletic training curriculum major to be implemented, and in the 1990's the American Medical Association formally recognized the profession of athletic training as an allied health care profession. From there, an individual accrediting body for athletic training was developed, and even further advancements were made in the athletic training curriculum. Athletic training education is still evolving and changing today to create better, more effective ways of educating young professionals.

Athletic training clinical education has evolved along with athletic training education. In 1959, the only clinical experience an athletic training student needed was six semester hours or an equivalent. In the 1970's, however, formal education guidelines emerged. Two different routes could be taken; one that required a formal education program with an approved curriculum, and the other was a hands-on "internship" position. Presently, athletic training students must be enrolled in a CAATE-approved program, and be supervised in clinical settings by a staff certified athletic trainer. 
The National Athletic Trainers' Association Education Council has identified a knowledge and skill base which it believes necessary for a person to possess in order to function as an entry-level athletic trainer. This has been termed the "educational competencies and clinical proficiencies." Both the competencies and proficiencies have been derived through information gathered by the NATA's role delineation study and are identified for all 12 domains of athletic training. These competencies and proficiencies are now a significant part of the athletic training student's clinical education.

The assessment of these skills is a key issue for health profession educators, and evaluation of these clinical proficiencies should be a measure of real-life application. There are many factors that interact in playing a part in a student's successful performance including learning over time, as well as the relationship between the approved clinical instructor and the athletic training student.

Since the induction of a certification examination to test the qualifications of an individual to become an entry-level athletic trainer, the format has changed dramatically. Every five years, the minimal competencies to practice as an athletic trainer and the standards of practice on the examination are revised. Presently the examination itself ensures that the athletic trainer has demonstrated knowledge and skill in the six practice domains including prevention, clinical evaluation and diagnosis, immediate care, treatment, rehabilitation and reconditioning, organization and administration, and professional responsibility.

This review of literature will discuss the evolution of athletic training education and clinical education, proficiencies and competencies, learning over time, the role of the athletic training student and clinical instructors, the evaluation of proficiencies and competencies, the evolution of the NATABOC, and the BOC examination. 
Evolution of Athletic Training Education Accreditation

Since athletic training education programs first appeared in the 1950's, a progressive evolution has taken place over the last five decades. ${ }^{2,20,39}$ Development of the athletic training education program occurred in 1956 with the appointment of the NATA Committee on Gaining Recognition. The role of this committee was "to study avenues through which the professionalization of athletic training could be enhanced." ${ }^{20,39}$ Three years later in 1959, the committee developed the first curriculum model of athletic training education. This model that was approved by the National Athletic Trainers' Association (NATA), was based on classes that already existed in a four-year college or university program which contained concentrations in physical education and health. The classes had two main areas of focus. ${ }^{20,39}$ The first was inclusion of classes that would help the student acquire a secondary-level teaching credentials due to the high demand for athletic trainers at the secondary school level. This was thought to enable the athletic trainer to be more marketable within the field of health or physical education. The second focus was to include classes that were prerequisites for physical therapy schools. This would allow the athletic trainer to further education goals, improve professional growth, as well as make the individual more employable. ${ }^{20,39}$

In 1969, the Committee on Gaining Recognition was re-named the Professional Advancement Committee, which was then sub-divided into the Subcommittee on Professional Education and the Subcommittee on Certification. ${ }^{20,39}$ The Professional Advancement Committee was re-named later and became the NATA Professional Education Committee (NATA-PEC), which was responsible for the recognition of the first undergraduate athletic training education programs. The recognition of these undergraduate programs also began the evaluation and approval process of the NATA athletic training curriculum. ${ }^{20,39}$ 
During the 1970s, the NATA Certification Committee administered the first national certification examination, and athletic training education experienced an increase in the number of athletic training programs. There were no significant changes in education made at this time by the NATA-PEC, only continual review and revision of course work as well as the clinical experience requirements. ${ }^{20,39}$

With an increase in the number of athletic training programs, there was also an increase in the number of athletic training students. This decreased the need for students to take physical therapy prerequisites and place more of a focus on the subject of athletic training. ${ }^{20,39}$ At this time it was felt that a teaching degree in health or physical education was actually limiting the student's chance of obtaining employment at the secondary level schools. It was thought that employment would be limited due to the number of students entering the field. However, teaching certification remained and the athletic training students continued earning teaching certification in academic majors other than health and physical education. ${ }^{20,39}$

Further improvement during the 1970's included development of a formal list of behavioral objectives that identified desired learning outcomes for the athletic training student by the NATA-PEC. These behaviors lead to the formation of the Competencies in Athletic Training in the early 1980s, and was the first step towards the recognition of a more specialized body of knowledge. This eventually led to the eleven courses that served as the framework of didactic athletic training education. ${ }^{20,39}$ The courses included anatomy, physiology, physiology of exercise, applied anatomy and kinesiology, psychology, first aid and safety, nutrition, remedial exercise, health (personal, community and school), based athletic training, basic athletic training, and advanced athletic training. ${ }^{20,39}$ 
In the 1980's, the NATA Board of Directors required an approved athletic training curriculum major to be implemented. Once created, the Guidelines for Development and Implementation of NATA Approved Undergraduate Athletic Training Education Programs were developed as the standards for the undergraduate athletic training program. ${ }^{20,39}$

A milestone in the history of the athletic training profession occurred in the 1990s. For the first time ever, the American Medical Association (AMA) formally recognized the profession of athletic training as an allied health care profession. Once recognized, the accrediting organization for the undergraduate programs changed from the NATA-PEC to the AMA Committee on Allied Health Education and Accreditation (CAHEA). ${ }^{20,} 39$ This was to gain the benefits of standardized education program requirements and external peer review by a highly regarded, specialized accreditation agency. Once CAHEA became the accrediting body for athletic training, the NATA-PEC combined with CAHEA to form a review committee for entrylevel allied health education programs. ${ }^{20,39,40}$ In 1991, the Guidelines for Development and Implementation of NATA Approved Undergraduate Athletic Training Education Programs were replaced with the Essentials and Guidelines for an Accredited Educational Program for the Athletic Trainer to meet the standards of the AMA continuing medical education. ${ }^{20,39}$

Once CAHEA was established, the AMA decided that the accrediting agency should be a self-supporting independent agency. Following that, CAHEA, now the Commission on Accreditation of Allied Health Education Programs (CAAHEP) was recognized by the United States Department of Education as an accrediting agency for educational programs. Thus, the Essentials and Guidelines for an Accredited Educational Program for the Athletic Trainer now became the Standards. ${ }^{20,39,40}$ 
On July 1, 2006, the Joint Review Committee for Athletic Training (JRC-AT) officially separated from CAAHEP (Commission on Accreditation of Allied Health Educational Programs) and became an independent specialized accreditor for athletic training. This was known as the Commission on Accreditation of Athletic Training Education (CATTE). All athletic training programs formerly accredited by CAAHEP were automatically accredited by CAATE. ${ }^{5}$ Because CAATE is now the accrediting body of athletic training; athletic training educational programs are now "in house." This is the first time in approximately sixteen years that the accrediting of athletic training education programs has now returned to the profession. ${ }^{5,20,39}$

Presently, the content of the athletic training curriculum must include formal instruction in the expanded subject matters as identified in the Athletic Training Educational Competencies. ${ }^{5}$ Formal instruction must involve teaching of required subject matter with instructional emphasis in structured classroom and laboratory environments. Athletic training curriculum subject matter requirements include prevention of injury/illness, evaluation of injury/illness first aid and emergency care, therapeutic modalities, therapeutic exercise, administration of athletic training programs, human anatomy, human physiology, exercise physiology, kinesiology/biomechanics, nutrition, psychology, personal/community health, and instructional methods. ${ }^{20}$ To evaluate clinical knowledge, the competencies are categorized according to 12 content areas comprising the role of the certified athletic trainer. These categories include risk management and injury prevention, pathology of injuries and illnesses, orthopedic clinical examination and diagnosis, and acute care of injury and illness. The categories also include pharmacology, therapeutic modalities, conditioning and rehabilitative exercise, medical conditions and disabilities, and nutritional aspects of injury and illness. Finally, psychosocial intervention and referral, health care administration, and professional development and responsibility are included as well. These 
content areas are sub-categorized according to behavioral classification, including Cognitive Competencies (knowledge and intellectual skills), Psychomotor Competencies (manipulative and motor skills), and Clinical Proficiencies (decision-making and skill integration). ${ }^{5}$

Evolution of Athletic Training Clinical Education

In recent years, athletic training education reform has become paramount. Given the importance of clinical education, an awareness of and appreciation for the background, history, and future directions of clinical education is valuable to clinician and educators alike. ${ }^{19}$ Much can be learned from the development and maturation of clinical education in medicine and other allied health care fields. Then, a current perspective of athletic training clinical education can be nurtured. $^{2}$

Clinical education has evolved along with athletic training education. In 1959, the only laboratory/clinical experience an athletic training student needed was six semester hours or an equivalent. In the 1970s, formal clinical education guidelines emerged. During this period of time, the NATA-PEC made a formal list of behavioral objectives that identified preferred learning outcomes for the athletic training student based on the 14 required courses. Instead of completing semester hours, a clinical clock-hour requirement and a skill-competence checklist were created to guide and monitor development of the students' clinical skills. The clinical requirements varied though, depending on whether the athletic training student was in an approved curriculum program or an internship program. These two different programs lead to two different routes for certification. ${ }^{20,37,39}$

The first route was within the context of a formal education program with an approved curriculum. The second route took a more hands on experiential route supplemented by a minimal amount of course work and an "internship" position. From the 1970's until early 2000s, 
students became clinically eligible to take the National Athletic Trainers' Association Board of Certification (NATABOC) examination by completing 600-800 clinical-experience hours in an approved curriculum program or 1800 clinical hours as an internship student (which changed to 1500 hours.) Additionally, students in both programs were required to complete clinical experiences with contact and collision sports. ${ }^{2,20,39}$ The internship route to obtain certification was eliminated in the 2004-2005 academic year. ${ }^{5}$

Presently, the clinical clock hour requirements that an athletic training student must meet to sit for the BOC examination were elimated. ${ }^{39,41}$ There is no mandated maximum number of clinical experience hours defined. It has been determined, however, that students involved in athletic training student experiences ( 20 hours/week) will be supervised by a staff certified athletic trainer. ${ }^{5,37,39}$ Athletic training students must be supervised at all times and the clinical instructor/approved clinical instructor must be able to intervene on behalf of the student and/or patient at all times. ${ }^{5,39}$ Athletic training students may perform athletic training skills only with direct supervision. Athletic training students cannot be required to perform any skills unsupervised. $^{5,39}$

According to the CAATE Standards for Accreditation of Entry-Level Athletic Training Education Program Standards, 38 "the length of clinical experiences should be consistent with other comparable academic programs requiring a clinical or supervised practice component. Such policies must be consistent with federal or state student work-study guidelines as applicable to the campus setting." 41 The other limitation is that "consideration must be given to allow students comparable relief (days off) from clinical experiences during the academic year as compared to other student academic and student activities offered by the institution (e.g., other health care programs, athletics, clubs). ${ }^{, 41}$ Another change is that the athletic training students are 
now required to be evaluated on various competencies and proficiencies set forth by the NATA Education Council. The competencies and proficiencies were a result of the NATABOC Role Delineation Study performed by the NATABOC. ${ }^{4}$

Clinical Education Today

Clinical education comprises a large portion of professional preparation in athletic training and other allied health care fields. Athletic training education can be described as the portion of the athletic training student's professional preparation that involves the formal acquisition, practice, and evaluation of clinical proficiencies through classroom, laboratory, and clinical experiences in medical care environments. ${ }^{2}$ It also has been defined as the hands-on experience involving clinicians, students, and patients in a real-life environment that provides a realistic component to a student's education. ${ }^{1}$ Certified athletic trainers perceive that about $53 \%$ of their entry-level professional development came from clinical education. ${ }^{2}$ In contrast to athletic training, physical therapy clinical education has been reported to be approximately $23 \%$ to $30 \%$ of the total curriculum. ${ }^{24}$

Clinical education, involving clinicians, students, and patients in a real-life environment, provides a realistic component to a student's education and has, therefore, remained a significant component of health care professional preparation. ${ }^{1}$ Because improvement in professional health care services depends on maintaining high-quality clinical education, clinical education appears to also be important to maintaining high quality athletic training services. ${ }^{1}$ Clinical education makes a substantial contribution to the professional preparation of athletic training students. ${ }^{1}$

Athletic training education programs must provide the proper type and amount of clinical supervision in order for athletic training students to obtain appropriate clinical education and to meet Board of Certification examination requirements. Athletic training students spend countless 
hours learning clinical skills in the classroom and laboratory setting, as well as integrating, applying, and mastering these skills as clinical proficiencies during clinical experience ${ }^{18}$ Clinical experiences are intended to provide the athletic training student with opportunities to integrate cognitive and psychomotor competencies, clinical proficiencies, and foundations of professional practice.${ }^{19}$ Clinical education involves the instruction and evaluation of clinical skills under the direct supervision of the Approved Clinical Instructor (ACI) who has completed appropriate training. ${ }^{19,37}$

Few limitations are placed on which activities constitute clinical education. The hands-on activities can include any experience that provides a practical or applied focus. For instance, students might practice psychomotor skills in a simulated environment on simulated patients. ${ }^{23,}$ ${ }^{37}$ Clinical education progresses from general technical skills to clinical competence, and students must learn to appreciate the affective aspects of their profession's distinctive working environment to develop necessary interpersonal and social skills and attitudes. ${ }^{23,37}$ Proficiencies and Competencies to Evaluate Clinical Skills and Didactic Knowledge

The National Athletic Trainers' Association Education Council has identified a knowledge and skill base which it believes is necessary for a person to possess in order to function as an entry-level certified athletic trainer. The knowledge and skills base has been termed as the "educational competencies and clinical proficiencies." The educational competencies make up the content that educational programs are to use in developing the curriculum and educational experiences for students. The clinical proficiencies define the common set of skills that entry-level athletic trainers should possess. Both the competencies and proficiencies are derived through prescriptive information gathered by the NATA's role 
delineation study and have been identified for each of the 12 domains of athletic training. (See Table B1)

Table B1. Twelve Educational Domains

1. Risk management and injury prevention

2. Pathology of injuries and illnesses

3. Injury assessment and evaluation

4. Acute care of injury and illness

5. Pharmacology

6. Therapeutic modalities

7. Therapeutic exercise

8. General medical conditions and disabilities

9. Nutritional aspects of injury and illness

10. Psychosocial intervention and referral

11. Health care administration

12. Professional development and responsibilities

Within each domain there are competencies classified as "cognitive," "psychomotor," "affective," and "clinical proficiencies." Cognitive competencies address knowledge and intellectual skills. Psychomotor competencies deal with manipulative and motor skills. Affective competencies address attitudes and values.

Clinical proficiencies involve decision making and application of the cognitive, psychomotor, and affective skills. The Joint Review Committee on Educational Programs in Athletic Training (JRC-AT) requires educational programs to teach and assess each of the educational competencies and clinical proficiencies.

The clinical competencies used by CAATE were created from the BOC Role Delineation Study and the NATA Education Council, and are updated and re-evaluated every five years. ${ }^{5,39}$ The competencies are comprised of knowledge and skills that are required of an entry-level athletic trainer. The twelve domains in the current edition of the Athletic Training Educational Competencies are the following: risk management, pathology, diagnosis, medical conditions, acute care, therapeutic modalities, exercise, pharmacology, psychosocial aspects, nutritional 
aspects, administration, and professional development. ${ }^{4,37}$ The competencies are further divided into three different domains; cognitive competencies, psychomotor competencies, and clinical proficiencies. Each of these domains is sub-divided into specific competencies and proficiencies. The athletic training student must demonstrate either proficiency or mastery in each of the competencies and proficiencies to be able to graduate and sit for the BOC certification examination. ${ }^{4,39}$ For a proficiency to be evaluated, there must be constant visual and auditory interaction between the student and the ACI that must be maintained. ${ }^{18,39}$

The fourth edition of the Athletic Training Educational Competencies contains the clinical proficiencies for effective preparation of the entry-level athletic trainer. ${ }^{3,4}$ The term "proficient" is defined in the fourth edition as "performing with expert correctness and facility." The clinical proficiencies represent "a listing of the student's clinical training before entering the profession" and guide decision making and skill integration. ${ }^{3,4}$ The proficiencies should be a measure of "real-life" application. The successful development of clinical proficiencies must represent a significant focus on the student's clinical experience, and the proficiencies must be organized in such a way that faculty and staff of the athletic training education program (ATEP) can evaluate and monitor student progress over time. ${ }^{3,4,41}$

One of the primary goals of clinical education is to aid in the acquisition, development, and mastery of these clinical proficiencies. ${ }^{3,6}$ It is important that proficiencies be evaluated in manners similar to applications in real life. Athletic training clinical proficiencies must be evaluated in a realistic fashion. Although a certified athletic trainer is thought to be competent upon passing the Board of Certification Examination, current testing methods do not necessarily evaluate clinical proficiencies. This responsibility lies with the accredited athletic training education programs. ${ }^{3}$ 
The primary goal in assessing the educational proficiencies is to evaluate the student's ability to successfully demonstrate the skills, not systematically perform from a checklist. The fourth edition of the Athletic Training Educational Competencies stated that if actual patients are not available for assessment of the clinical proficiencies, then standardized or simulated patients or scenarios should be used to evaluate students. ${ }^{3,4}$

The findings from a study about the evaluation of student's clinical proficiencies by Walker $^{2,3}$ found that although some athletic training education programs appear to have a sufficient number of ACIs, the timely occurrence of an injury or condition continues to be a barrier to real-time clinical proficiency evaluation. Approved Clinical Instructors also felt that they were unable to spend adequate time with students who needed to complete their evaluations. Walker's findings support that it may be increasingly difficult for today's collegiate athletic trainer to find adequate time to accept extra responsibility for teaching and evaluating athletic training students' clinical proficiencies. ${ }^{2,3}$ The general trend is toward increased workloads to provide medical care coverage for expanding sport seasons and off-season conditioning, practice, and competition schedules, with fewer resources and more pressures. Greater responsibility for the teaching, supervising, and assessing of students may be unrealistic. ${ }^{3}$ Influential Factors in Evaluating Proficiencies

Accurately assessing students' clinical skills is a key issue for health profession educators. Student clinicians must perform the skills correctly and safely on real patients before they can begin entry-level practice. Therefore, athletic training clinical proficiencies should be a measure of real-life application. ${ }^{7}$

A study by Armstrong ${ }^{7}$ discussed appropriate methods for evaluating clinical proficiencies from accredited athletic training education programs in the Great Lakes Athletic 
Trainers' Association. The study used a 15 item survey instrument to assess differences among ACI demographic characteristics and methods, barriers, educational content areas, settings, and opportunities for feedback regarding clinical proficiency evaluation. The study concluded that most clinical proficiencies are evaluated through simulations, and athletic training education program administrators should develop alternative methods of clinical proficiency evaluations.

Most approved clinical instructors use simulations to evaluate clinical proficiencies, but these simulations may have questionable quality for real-life application. There are many other factors that interact and play a part in the overall successful outcome in assessing a student's performance. ${ }^{7}$ The ability to demonstrate learning over time into the evaluation and also into the classroom every day is important, as is the relationship between the ACI and athletic training student.

Learning over time: Clinical education in athletic training, as in numerous allied medical professions, depends upon clinical experiences as a critical component for student learning. ${ }^{11}$ The responsibility to provide quality clinical education experiences within athletic training education programs is increasing dramatically. Certainly the standards for athletic training education programs (from the Commission on Accreditation of Allied Health Programs (CAAHEP) reflect increased accountability in this area. ${ }^{19}$ Availability of high-quality clinical education settings is vital to the profession of athletic training. Unfortunately, simply spending time in clinical education settings such as the athletic training room, or other clinical affiliation sites, does not ensure that students acquire clinical skills. ${ }^{19}$

In a study by Berry ${ }^{25}$, undergraduate athletic training students' perceptions of how time is utilized during clinical field experiences were examined. Program Directors at 131 CAAHEPaccredited athletic training programs were surveyed. Results showed that the type of clinical 
field-experience setting and clinical assignment affects the amount of time spent in active learning. One suggestion for educators to maximize student learning time, is to lengthen the available opportunity time. This, however, does not guarantee an increase in the quality of education.

The focus in clinical education settings must include educational standards and experiences designed to augment students' knowledge and to promote their professional maturity. ${ }^{19}$ The clinical setting provides validation of previously learned principles and concepts; moreover, clinical skills are learned and practiced in simulated environments. ${ }^{19}$ Ideal clinical experiences are closely relevant and timely to what is being taught in concurrent courses and allow continued reinforcement and practice of what has been learned. Such experiences are vital to a student's development of competence, self-confidence, and flexibility in unfamiliar situations. $^{19}$

Presently, athletic training educators are teaching many competencies and proficiencies to entry-level athletic training students. Critical thinking is needed in clinical decision making because of the many changes occurring in education, technology, and health care reform. ${ }^{38}$ Athletic training educators fostered more critical thinking in their learning objectives and written assignments than their examinations. The disposition of athletic training students to think critically exists but it is weak. ${ }^{34,38}$

In a study by Fuller ${ }^{31}$, undergraduate athletic training educators were evaluated to determine if writing learning objectives and giving written assignments and examinations that foster critical thinking skills were being used. Thirty institutions were asked to provide their curriculum materials for the study, and the results indicated that educators fostered more critical thinking in their learning objectives and written assignments than their written exams. 
In another study using undergraduate athletic training students, Leaver-Dunn ${ }^{34}$ investigated whether the tendency to think critically, the likelihood of using specific components of critical thinking, and the effect of selected demographic and educational variables on criticalthinking are being used. Ninety-one students were evaluated, with results showing that athletic training students are inclined toward critical thinking, but the tendency is weak. Classroom and clinical instructors should use teaching methods and techniques that facilitate the components of critical thinking.

Students should be encouraged to be inquisitive, ask questions, and not believe and accept everything they are told. Faculty should be aware of their course goals and learning objectives; if these are stated as higher-order thought outcomes, then activities that promote critical thinking should be included in classroom activities and assignments. ${ }^{38}$ The promotion of critical thinking and critical thinking skills has implications for athletic training education and the advancement of athletic trainers and the profession of athletic training. ${ }^{34,38}$

The formal process of learning over time has recently been introduced as a required way for athletic training educational competencies and clinical proficiencies to be delivered and mastered. ${ }^{25}$ Learning over time incorporates the documented cognitive, psychomotor, and affective skills associated with the acquisition, progression, and reflection of information. This method of academic preparation represents a move away from quantitative-based learning module toward a proficiency-based mastery of learning. ${ }^{28}$

Athletic training, similar to many other professions, has always required the learning of clinical proficiencies. Students practice these skills many times before final testing. At no time were the skills and proficiencies taught, tested once, and then forgotten. ${ }^{25}$ What has changed pertaining to learning over time is that the required proficiencies are presented early in the 
academic program and formally assessed in a logical progression. Prior planning and the need for documentation of testing has not become a key component for student learning in the overall education process. ${ }^{28}$

By definition, learning over time is the documented, continuous process of skill acquisition, progression, and student reflection. This concept reinforces the demonstration of a systematic progression through the cognitive, psychomotor, and affective domains within different educational settings. ${ }^{28}$ Learning opportunities may vary from structured classrooms and laboratory settings to clinical rotations consisting of practicums, internships, and field experiences. $^{28}$

Learning over time, in relationship to clinical proficiencies, should focus on the "big picture." Individual psychomotor skills are important for all athletic trainers; however what is needed by students to become entry-level athletic trainers should not be forgotten. ${ }^{28}$ Students must be able to evaluate a head injury, treat an acute injury, and design a rehabilitation program. The big picture is not based on skills alone, but incorporates many specific psychomotor, cognitive, and affective competencies into meaningful clinical outcomes. Mastery of clinical proficiencies enables the student to select, administer, and interpret results. ${ }^{28}$

The role of athletic training students and clinical instructors: Students in clinical education are primarily concerned with learning and practicing clinical skills. Therefore, the clinical setting should have an adequate variety and number of patients along with adequate equipment and resources. The range of experience with patients and athletes should include screening, evaluating, planning, treating, providing follow-up care, and reporting. ${ }^{13,19}$

Athletic training students spend many hours in the clinical setting working with a variety of patient populations in an attempt to learn the skills necessary to become competent certified 
athletic trainers. ${ }^{15}$ Competence, whether it occurs in the classroom or in the clinical placement, requires that students be provided with adequate time to learn and that this time be used constructively. Athletic training educators generally agree that exposing students to quality clinical placements is as important as providing them with appropriate classroom instruction. ${ }^{15}$ Athletic training educators should try to identify how students' time is managed. This is the first step in developing clinical placements to maximize student learning and promote professional development. ${ }^{15}$

In clinical education settings, students practice and develop psychomotor skills and incorporate the attitudes, values, and beliefs of professional practice. A key component of student development in the clinical setting is the quality of clinical instruction. ${ }^{13,18,19}$ Athletic trainers recognize that they hold the role of clinical instructor (CI) and report that clinical instruction represents a large portion of their daily responsibilities. Contributing factors in the successful implementation of the clinical education component of athletic training education are the development, training, and evaluation of quality CIs. ${ }^{18}$

All staff members should be practicing ethically and legally as outlined by code of ethics, the state standards on practice, the state practice act, and the clinic or athletic training program policy. ${ }^{19}$ The policy should include statements on patients' rights, release of confidential information, photographic permission, clinical research, and procedures for reporting unethical, illegal, or incompetent practice. All standards of practice should be documented in writing. ${ }^{13,19}$

The relationship between the $\mathrm{CI}$ and the student is a unique teacher-student phenomenon, allowing for an individualized clinical experience designed to meet the needs of the student as well as the objectives of the athletic training education program. Quality clinical instruction is more important to facilitate student learning of cognitive, psychomotor, and affective domains 
fundamental to clinical practice. ${ }^{13,18,19}$ Many certified athletic trainers involved in athletic training education programs (ATEPs) serve as CIs. Clinical instructors may teach, evaluate, and supervise athletic training students in clinical education field experience. ${ }^{13,18,19}$ These individuals are expected to provide quality learning experiences for athletic training students and do demonstrate sound $\mathrm{CI}$ behaviors and characteristics.

Supervising athletic trainer behaviors have a profound effect on the professional development of student athletic trainers. Interaction between supervisors and students positively or negatively affect student athletic trainer's growth and development. A study by Curtis ${ }^{42}$ identified and described helpful and hindering clinical teaching behaviors of athletic trainers, as perceived by student athletic trainers. The study examined sixty-four athletic trainers with students reporting on helpful and hindering behaviors via several categories including mentoring behaviors, professional acceptance behaviors, nurturing behaviors, and modeling behaviors. Results showed that students reported more helpful than hindering behaviors, and showed that student athletic trainers wanted to be respected as professionals regarding ability and knowledge. They also desired mentoring through explanation, demonstration, and constructive feedback and nurturing. ${ }^{42}$

Clinical instructors serve an important role in the facilitation and integration of athletic training knowledge and skill. ${ }^{17}$ Clinical instructors should model professional behavior to best facilitate student learning. ${ }^{17}$ Clinical instructors and ACIs alike should possess characteristics including enthusiasm, interpersonal relations, sensitivity to students, and receptiveness to suggestions. ${ }^{13,18,19}$

Communication is one of the most important leadership skills to develop to become an effective leader. It is imperative for the future of the athletic training profession that certified 
athletic trainers continue to develop effective leadership skills to address the changing times in education and expectations of the athletic training profession. ${ }^{43}$

Another useful skill for a CI or ACI to obtain is recognition of a teachable moment. A teachable moment in the athletic training setting occurs when a CI or ACI and an ATS actively participate and interact with each other to enhance learning and foster intellectual curiosity in the clinical education environment. ${ }^{36}$ Realization of these moments and an ability to use them as a means to educate the student has been shown to enhance the student's learning. ${ }^{36}$

Foster $^{30}$ conducted a study in 1992 to describe the clinical teaching roles of athletic trainers. Athletic trainers with teacher preparation and experience developed broader clinical instruction activities and had stronger positive clinical instruction options than do athletic trainers without teaching backgrounds. ${ }^{30}$ Young athletic trainers with less than six years experience have a hard time finding time for clinical teaching. The study also showed that athletic trainers with a master's or higher degree show broader teaching activities than athletic trainers with baccalaureate professional preparation. ${ }^{30}$

Evaluation: Athletic training involves the application of knowledge. Clinical decision making involves surveying a situation, establishing needs, and then determining a course of action that will meet those needs. ${ }^{44}$ An adequate knowledge base is required to establish needs and determine the appropriate action. The greater the knowledge base, the greater the possibility that the clinical decision will lead to a more complete resolution of the problem. ${ }^{44}$ Therefore, the more effective the classroom instruction is, the better the clinical decision making will be and the better the health care for the patient. ${ }^{44}$ Athletic training is the application of knowledge. Without good clinical education, much of the classroom education is wasted. ${ }^{44}$ 
Athletic training education, like other disciplines, will benefit from reevaluation of teaching methods in light of the fact that our cultural environment is vastly different than it was 13 years ago, thanks to the technologic revolution and the availability of information. ${ }^{32}$ Traditional teaching methods, like lecture formatting, may no longer be the most effective strategy for today's culture, where critical skills include problem solving and decision making. ${ }^{32}$ Problem-based learning, grounded in cognitive theory and medical education, is a useful approach in teaching students how to think critically and solve problems they will encounter in the athletic training professional environment. ${ }^{32}$

Because athletic training education combines traditional classroom learning with clinical experiences, the two settings are very distinct. In the classroom setting, criterion tasks can only be simulated at best, while the clinical setting is designed to provide real-life experiences. Consequently, the preferred way in which students process information may be quite different in these two settings. ${ }^{29}$ In a study by Coker,${ }^{29}$ it was shown that learning styles can shift depending on the domain through which an individual is learning. Therefore, teaching strategies incorporated in one setting may not be as equally effective in the other setting. Each learning setting should be treated separately in order to accommodate individual learning styles and maximize learning achievement.

National Athletic Trainers Association Board of Certification

The Board of Certification, Inc. (BOC) is the only accredited certification program in the United States, and it sets the standards for the practice of athletic training. ${ }^{16}$ It was incorporated in 1989 to provide a certification program for entry-level Athletic Trainers. The entry-level certification program is designed to establish standards for entry into the athletic training 
profession. The BOC provides a certification program for the entry-level Athletic Trainer and establishes requirements to maintain status as a Certified Athletic Trainer (AT). ${ }^{16}$ Board of Certification Examination

Since the induction of a certification examination to test the qualifications of an individual to become an entry-level athletic trainer, this format has changed dramatically. Initially the National Athletic Trainers Association Board of Certification (NATABOC) Examination allowed official recognition of individuals who meet the standards for the practice of athletic training set by the Board of Certification (BOC). At that time, individuals were able to sit for the examination as long as they were enrolled in their final semester of a CAATEaccredited program, the examination application was endorsed by a recognized Program Director, and they had evidence of current certification in Emergency Cardiac Care (ECC). The examination was conducted five times a year at various locations throughout the United States. It was comprised of three sections. The first section was a written section of multiple choice questions which were generally content-driven. The second section included a written simulation assessment which included circumstances related to athletic training which was designed to mirror real-life decision making procedures. Finally, the third section was a practical section which assessed skills required for athletic training.

The Board of Certification, Inc. (BOC) regularly conducts a Role Delineation Study (RDS) within a sample of certified athletic trainers. These investigations determine the current role, or standards, of the profession. This process is often referred to as a "job analysis." The RDS establishes the minimal competencies to practice as an athletic trainer and thus reflects the contemporary standards of practice for the athletic training profession. ${ }^{39,45}$ The BOC Role Delineation Study was a study performed to determine whether the National Athletic Training 
Certification Examination had content validity. ${ }^{39,45}$ Ensuring content validity on the BOC certification exam is one way to demonstrate that the examination appropriately evaluates the knowledge and skills needed to function as a component entry-level athletic trainer. The areas tested in the exam measure the knowledge and skills essential for the profession and reflect the tasks performed in the range of practice settings throughout the United States. The study represents the importance, criticality, and relevance of the practice of athletic training. ${ }^{39,45}$

The BOC examination ensures that the athletic trainer has demonstrated knowledge and skill in six practice areas or domains. (Table 2$)^{16}$

Table B2. Athletic Training Domains

1. Prevention

2. Clinical Evaluation and Diagnosis

3. Immediate Care

4. Treatment, Rehabilitation and Reconditioning

5. Organization and Administration

6. Professional Responsibility

Additionally, the BOC has established the continuing education requirements that a Certified Athletic Trainer must satisfy in order to maintain current status as a BOC Certified Athletic Trainer. On a regular basis, the $\mathrm{BOC}$ reviews the requirements for certification eligibility and the standards for continuing education. ${ }^{16}$ Additionally, the Board reviews and revises the certification exam in accordance with the exam specifications of the BOC Role Delineation Study that is reviewed and revised every five years. ${ }^{16,45}$ The most present Role Delineation Study includes the percent of questions on the exam for each domain. (Table 3$)^{16,45}$

Table B3. Athletic Training Domains and \% of Questions on Exam

\begin{tabular}{lc}
\hline Prevention & $15.72 \%$ \\
Clinical Evaluation and Diagnosis & $22.91 \%$ \\
Immediate Care & $17.50 \%$ \\
Treatment, Rehabilitation and Reconditioning & $23.31 \%$ \\
Organization and Administration & $11.29 \%$ \\
Professional Responsibility & $9.27 \%$ \\
\hline
\end{tabular}


Presently, the BOC is a computerized test that consists of two separate parts; one multiple choice section, and a hybrid section. The multiple choice section consists of a minimum of 125 multiple-choice items, including 15 unscored items, 5 "alternative" items which include drag and drop, text based simulation, multi-selection, and hot spot, and 2 five-item focused testlets. These consist of a scenario followed by five key/critical questions related to that scenario, and may include any of the item types. The hybrid section describes a scenario, and gives the candidates the opportunity to select the order in which to treat or resolve the situation. Once this selection is made, questions are asked about the specific decisions. ${ }^{9,10}$

Instrumentation Tools

Little research has been conducted dealing with the creation of an assessment tool within the field of athletic training. Many institutions have their own way of grading and assessing their students, and no one method of widely assessing student performance on proficiency skills has been developed.

Skills for assessing patients with musculoskeletal conditions are critical in the athletic therapy, athletic training, and physical therapy professions. Teaching assessment skills are important and challenging as well, especially if no educational standards are associated with them. A technique that athletic therapists in Canada use to assess orthopedic conditions was content validated and resulted in the presentation of the Standardized Orthopedic Assessment Tool (SOAT). ${ }^{8}$

The SOAT was originally developed to evaluate athletic therapy students during a 30minute period through expert evaluation by 2 raters and 1 standardized patient. The major categories of the SOAT comprise history, observation, scanning examination, clearing joints above and below the lesion site, examination, special testing, palpation, and diagnosis. ${ }^{8}$ Each 
category includes a checklist and a global rating scale. The original SOAT focused on 6 regions of the body, including the shoulder, elbow, wrist and hand, hip, knee, foot and ankle. This study focused on three body parts that educators found were areas of most injury, including the shoulder, knee, and ankle. Results of the original and the second-implemented study showed that the SOAT has promise as an effective instrument in measuring performances of athletic therapy students. ${ }^{8}$ Before the SOAT, no tool to measure orthopedic assessment skills had been described in the literature.

A standardized tool to measure orthopedic assessment skills is important in educational settings. Classroom-based assessment rarely goes beyond face validation, which limits its generalizability beyond a specific school. ${ }^{8}$ Athletic training professions are accountable for providing a standardized accredited curriculum. Professional standards are in place to protect the public. Educational institutions must work in concert with professional governing bodies, and certifying agencies to ensure standards are maintained. ${ }^{8} \mathrm{~A}$ standardized assessment tool provides a mechanism to maintain standards through constructive alignment with professional competencies that tie all shakeholders to each other. Assessment completes the teaching and learning cycle, and the assessment tool is merely the mechanism that facilitates the cycle. The process of tool development is critical and must be planned carefully to build an accurate measurement of the underlying construct. ${ }^{8}$

Outcome assessment is necessary for all education programs, and administrators, accreditors, legislators, and prospective students often demand proof of a program's success and how it compares to others. ${ }^{9}$ Accreditation standards for athletic training programs require the routine assessment of outcomes related to clinical and didactic instruction, student learning, and overall program effectiveness. As required for accreditation, numerous institutional and 
programmatic systems have been developed over the years, some with and most without universal methods that would allow for comparison between programs. The lack of standard criteria among different institutions is a major roadblock to a comparison that would allow programs to gauge their performance against a reference or other similar programs. ${ }^{9,10}$

A wide variety of outcomes are commonly used to measure the success of a program. An even wider variety of methods are used to assess each outcome. Collection and analysis of data is often the most difficult aspect and largest hindrance to program improvement. ${ }^{9}$ Creating an instrument that will allow program directors to measure outcomes year after year in a consistent manner with a standardized methodology, one that is easy to implement, and whose results are user-friendly is needed to determine outcomes. Assessment systems should also work seamlessly with, and be incorporated into curriculum designs so that they do not require large amounts of effort and time. ${ }^{9}$

A recent study by Carr $^{9}$ created an assessment instrument that has been developed on the above principles. The Online Assessment of Athletic Training Education (OAATE) instrument was created to get an idea of how well students are being taught and what factors can be controlled that influence their learning. The online instrument's initial bank of assessment questions was developed based upon the 12 domains of the $3^{\text {rd }}$ Educational Competencies and Proficiencies, which was the current version as this project was begun. A minimum of ten multiple choice questions with four possible answers were collected from Athletic Training educators for each of the 12 domains. Three of the domains were populated with more than ten questions. For the exam, the instrument randomly generated ten questions for each domain for a total of 120 questions. After completing a brief demographic survey, the students were prompted to begin the content knowledge assessment. The students had ten minutes to complete each 
domain and were directed to go in order. Students had access to the test portion of the web site for 30 days and could go at their own pace. ${ }^{9}$

Results of this study showed that drawing conclusions based upon the individual domain scores is not reliable, but the use of the overall scale score was reliable. The study was also conducted using the older version of the Education Competencies, which will be modified to match the newest versions in the future. It was realized that program personnel consider all available data sources when deciding when and how to modify a curriculum. Continuous measurement for continuous improvement requires the same measures be completed year after year. $^{9}$

Summary

A progressive evolution of athletic training education programs has taken place over the last five decades. Athletic training has been recognized as an allied health care profession, and many improvements have been made in learning and educational curriculum objectives. Clinical education has evolved with athletic training education to include clinical requirements, and supervision rules and regulations for athletic training students.

The National Athletic Trainers' Association Education Council has identified a knowledge and skill base which is believes is necessary for a person to possess in order to function as an entry-level certified athletic trainer. These competencies and proficiencies are derived through information gathered in the NATA's role delineation study and are based around the 12 domains of athletic training.

Clinical education comprises a large portion of professional preparation in athletic training, and is the portion of the athletic training student's education that involves the formal 
acquisition, practice, and evaluation of clinical proficiencies through classroom, laboratory, and clinical experiences in medical care environments.

Accurately assessing student's clinical skills is an issue for health profession educators. Student clinicians must perform the skills correctly and safely on real patients before they can begin entry-level practice. Therefore, assessment of the athletic training clinical proficiencies should be a measure of real-life application.

There are many influences on the way proficiencies are evaluated. The formal process of learning over time has recently been introduced as a required way for athletic training educational competencies to be delivered and mastered. Critical thinking is also needed in clinical decision making because of many changes that are occurring in education, technology, and health care reform. The relationship between the clinical instructor and the student athletic trainer is unique and allows for an individualized clinical experience designed to meet the needs of the student as well as the objectives of the athletic training education program. Clinical instructors teach, evaluate, and supervise athletic training students in clinical education field experience, and are expected to provide quality learning experiences for athletic training students. Athletic training is the application of knowledge, and the more effective the classroom instruction is, the better the clinical decision making will be and the better the health care will be for the patient.

Since the induction of a certification examination to test the qualifications of an individual to become an entry-level athletic trainer, its formatting has changed dramatically. The BOC's Role Delineation Study is reviewed and revised every five years and establishes the minimal competencies to practice as an athletic trainer. It also reflects the standards of practice on the examination for the athletic training profession. The test itself ensures that the athletic 
trainer has demonstrated knowledge and skill in the six practice domains including: prevention, clinical evaluation and diagnosis, immediate care, treatment, rehabilitation and reconditioning, organization and administration, and professional responsibility. Presently, the BOC is a computerized test that consists of two separate parts; a multiple choice section and a hybrid section.

There has not yet been a widespread method for athletic training programs to evaluate proficiencies, but guidelines as to how they should be approached have been established. With recent advancements in teaching methods, educational programs and testing methods are becoming more technology based as well. Creating and developing a tool that could standardize the evaluation of clinical proficiencies in the athletic training setting is a groundbreaking idea whose potential has not yet been measured. 


\title{
APPENDIX C
}

\section{ADDITIONAL METHODS}

\section{Table C1. Cover Letter}

\section{WestVirginiaUniversity \\ College of Physical Activity and Sport Sciences}

Your help is needed!

You have been hand selected to participate in a research study based on your educational experience as a senior athletic training student at West Virginia University. My name is Shannon Baldwin and I am a Graduate Athletic Training Student and Graduate Assistant ATC at West Virginia University. I will be conducting a study with the primary investigator Michelle A. Sandrey PhD, ATC to fulfill requirements for a Master's thesis and to complete a MS degree in Athletic Training. Both are affiliated with West Virginia University.

I am writing you to request your participation of this research study titled: The use of a Proficiency-Based clinical Tool in the Evaluation of Clinical Knowledge and Skills in the Athletic Training Setting. The purpose of this study is to create a clinical proficiency evaluation tool which can consistently evaluate an athletic training student's required proficiency and competency skills. The intent is to provide West Virginia University a ground breaking and technology-based alternative method for consistency in testing clinical proficiencies. Ultimately, the goal is to standardize the way proficiencies skills are determined and evaluated between athletic training programs throughout the nation. In order to accomplish this, I am requesting your assistance.

This is an excellent opportunity for you to take part in the fundamental research that could help improve athletic training education. The process will include a release of your transcripts, proficiency grades and clinical site evaluation grades. Then you will be allowed the opportunity to complete a clinical proficiency evaluation tool using an exam format consisting of 50 interactive multiple choice questions. You will not have to answer every question. It will take roughly 50 minutes to complete the examination, which will be administered in your practicum class.

Your participation in this research is extremely important and will provide you with the opportunity to help develop a clinical evaluation tool that may shape the future of athletic training education. Your participation in this study will not affect your classroom grades, and if you are willing to participate in this study your responses are completely confidential.

I would like to thank you in advance for your willingness to participate.

Kind Regards,

Shannon L. Baldwin, ATC, NCSF-CPT

\author{
Department of Coaching and Teaching Studies: Athletic Coaching Education; Physical Education \\ Teacher Education \\ Department of Sport Sciences: Athletic Training, Sport and Exercise Psychology; Sport Management


* West Virginia University Institutional Review Board acknowledgment of this study is on file Table C. Informed Consent Forms

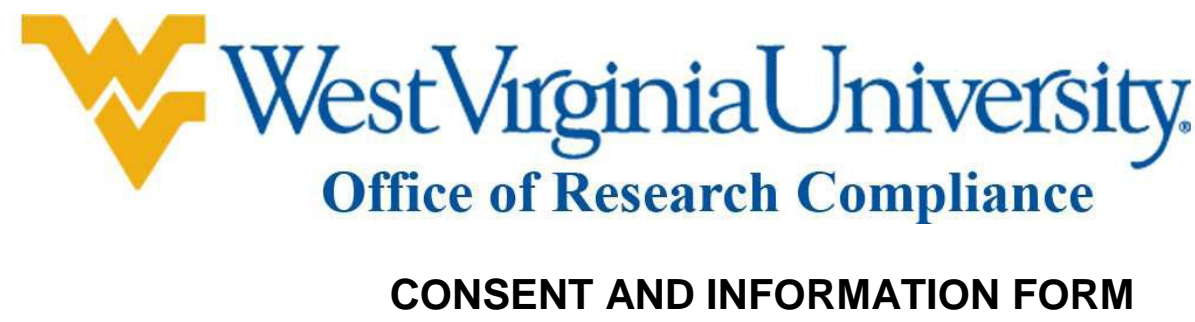

A clinical tool for proficiency knowledge assessment

Principal Investigator: Sandrey, Michelle

Department:

Physical Education

Tracking Number:

\section{Study Title:}

The Use of a Proficiency-Based Clinical Tool in the Evaluation of Clinical Knowledge and Skills in the Athletic Training Setting

\section{Co-Investigator:}

Baldwin, Shannon

\section{Sponsor:}

$\mathrm{N} / \mathrm{A}$

\section{Contact Persons}

In the event that you experience any side effects or injury related to this research, you should contact Shannon Baldwin, ATC, NCSF-CPT (717)808-9971 sbaldwi1@mix.wvu.edu. If you have any questions, concerns, or complaints about this research, you can contact Dr. Michelle A Sandrey PhD., ATC at (304)293-0870 or msandrey@mail.wvu.edu.

For information regarding your rights as a research subject, you may contact the Office of Research Compliance at 304/293-7073.

\section{Introduction}

You, , have been asked to participate in this research study, which has been explained to you by Shannon Baldwin ATC, NCSF-CPT. This study is being conducted by the principle investigator Michelle A. Sandrey PhD., ATC and investigator Shannon Baldwin ATC. This research is being conducted to fulfill the requirements of a thesis project in athletic training in the College of Physical Activity and Sport Sciences at West Virginia University, under the supervision of Dr. Michelle A. Sandrey PhD., ATC. 


\section{Purpose of the Study}

The purpose of this study is to create a clinical proficiency evaluation tool to consistently evaluate an athletic training student's required proficiency competencies with on-the-field experiences.

\section{Description of Procedures}

This study will be conducted at the WVU Coliseum in Room 136A located on Monongahela Blvd. Morgantown, WV 26505. Testing will be done in accordance with a regularly-scheduled senior practicum class in the student's normal classroom. This environment allows the students the ability to hear and understand all written and verbal directions in a quiet atmosphere that is free from distractions.

At an initial meeting, the purpose of this study will be explained to you. If you are interested in participating in the study and taking the evaluation tool examination, you will be given a Family Educational Rights and Privacy Act (FERPA) one-time use form. This form will give the investigators permission to access individual scholastic files since acceptance into the athletic training education program through the fall 2009 semester. This allows personal information including athletic training GPA, competency and clinical performance evaluation grades, proficiency grades, and the clinical proficiency evaluation tool grades to be released. You do not need to release all information in order to be an eligible subject. All forms and released information will be kept confidential. This will conclude the first meeting.

You will be given the evaluation tool one time by your undergraduate program director in accordance with your practicum classes in the middle to end of February. Brief instructions will be given at the beginning of the tool, and a sample problem will be presented. Then the proficiency evaluation tool video will begin. Upon completion of the examination, you will be asked to place answer sheets in an envelope in front of the room.

\section{Risks and Discomforts}

There are no known or expected risks from participating in this study except for the time loss during the practicum class while the tool is being administered. You understand that the tool itself could trigger mild frustration associated with completing and submitting answers before moving to the next questions. You may experience minor stress based on the "test" question format through the answer sheet, however use of similar tools used in the athletic training setting has not resulted in comments indicating frustration or stress with the process since it does not directly affect the student's academic grades. If an adverse physical or psychological 
reaction were to occur during any portion of this study, appropriate care or referral to the Caruth Center will be made available.

\section{Alternatives}

You do not have to participate in this study.

\section{Benefits}

You will acquire experience in taking an examination that is consistent with your required proficiency and competencies through the athletic training program. This tool covers items through your entire time in the athletic training program, which is a great mechanism for showing learning over time. As you complete the tool, you also gain experiences in preparation and review for your upcoming Board of Certification (BOC) examination.

\section{Financial Considerations}

There will be no cost as a result of participation in this study. You understand that you will not receive any monetary compensation for participation in this study.

\section{Confidentiality}

Subject's Name:

Student's 700 ID Number:

I understand that information about your academic information is private. I am dedicated to protecting the privacy of that information. Because of this promise, I must get your written authorization (permission) before I may use or disclose your scholastic information. This form and the FERPA form give that permission. It also helps me make sure you are told correctly how this information will be used or disclosed. Please read the information below carefully before signing this form. Please ask any questions you may have about these forms and their uses. You can decide to sign or not sign this authorization form. However, if you choose not to sign this authorization form, you will not be able to take part in this study. Whatever choice you make about your participation, it will not have an effect on your course grades.

USE AND DISCLOSURE COVERED BY THIS AUTHORIZATION. DO NOT SIGN A BLANK FORM. You or your authorized representative should thoroughly read the information below before signing this form. This form will authorize the following person(s), class(es) of persons, and/or organization(s) to disclose, use, and receive the information: WVU, Michelle A. Sandrey, PhD., ATC, Shannon Baldwin, ATC, NCSF-CPT. The research site(s) carrying out 
this study includes WVU. If, during the course of the research, the institution listed above merges with, or is purchased by, another company or institution, this authorization to use or disclose protected academic information in the research will extend to the successor company or institution.

SPECIFIC UNDERSTANDINGS By signing this research authorization form, you give permission for the use and/or disclosure of your protected academic information described above. The purpose for the uses and disclosures you are authorizing is to carry out the study explained to you during the informed consent process. It is also to ensure that the information relating to the study is available to all parties who may need it for research purposes. This information may be re-disclosed or used for other purposes if a recipient described in this form is not required by law to protect the privacy of the information. You have a right to refuse to sign this authorization. Your grade in practicum class or any other practicum class will NOT be affected if you do not sign this form. However you will NOT be able to take part in the study described in this authorization if you do not sign this form. If you sign this authorization, you will have the right to cancel it at any time, except to the extent that WVU has already taken action based upon your authorization or needs the information to complete analysis and reports of data for this study. To cancel this authorization, please write to the Principal Investigator, Michelle A. Sandrey, Ph.D, at: West Virginia University, PO Box 6116, Morgantown, WV 26506. You will NOT be allowed to see or copy the information described on this form as long as the research is in progress, but you have a right to see and copy the information upon completion of the research in accordance with hospital policies. You have a right to receive a copy of this form after you have signed it. Expiration Date: NONE In any publications that result from this research, neither your name nor any information from which you might be identified will be published without your consent.

THE SUBJECT OR HIS/HER AUTHORIZED REPRESENTATIVE MUST BE PROVIDED WITH A COPY OF THIS FORM AFTER IT HAS BEEN SIGNED.

SIGNATURE

I have read this form and all of my questions about this form have been answered. By signing below, I acknowledge that I have read and accept all of the above.

Signature of Subject or Authorized Representative 
Date

Print Name of Subject or Authorized

Representative

Print Name of Individual Explaining this Research Authorization Form

CONTACT INFORMATION: The contact information of the subject or authorized representative who signed this form should be filled in below.

Address

Telephone: (daytime) (evening)

E-mail Address (optional):

Voluntary Participation

Participation in this study is voluntary. You are free to withdraw your consent to participate in this study at any time. Refusal to participate or withdrawal will not affect your class standing or your grades and will involve no penalty to you. In the event that new information becomes available that may affect your willingness to participate in this study, this information will be given to you so that you can make an informed decision about whether or not to continue your participation. You have been given the opportunity to ask questions about the research, and you have received answers concerning areas you did not understand.

Upon signing this form, you will receive a copy.

I willingly consent to participate in this research.

Signature of Subject or

Printed Name

$\overline{\text { Date }} \overline{\text { Time }}$

Subject's Legal Representative

The participant has had the opportunity to have questions addressed. The participant willingly agrees to be in the study.

Signature of Investigator

Printed Name

Date

Time 
Table C3. FERPA Forms

FERPA One Time Use Form

West Virginia University

Picture ID Required

Family Educational Rights and Privacy Act Release

Please print:

Student Name:

Last First Middle

Address:

\begin{tabular}{cccc}
\hline Street & & \\
& & \\
\hline City & State & Zip
\end{tabular}

Phone:

$\square \square \square-\square \square \square-\square \square \square \square$

Student ID:

$\square \square \square \square \square \square \square \square \square \quad$ Date of Birth

Date of Birth:

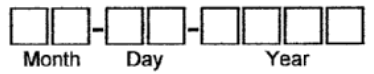

The Family Educational Rights and Privacy Act (FERPA) is a Federal law that protects the privacy of student education records. I understand that (1) I have the right not to consent to the release or disclosure of my education records; (2) I have the right to inspect and review such records upon request; and (3) this consent to release or disclose shall remain in effect for this one request only or sooner, if revoked by me, in writing, and delivered to the person at the office named below. Any disclosure of information made by WVU prior to expiration or receipt of revocation is not affected by expiration or revocation. I further understand that in order for WVU to release information to the recipient named below, this release must be signed. Therefore, I, the undersigned, expressly authorize the official/office identified in Section 1 to release my education records which are identified in Section 2 to the person/entity identified in Section 3.

1. WVU OFFICIAL(S)/ OFFICE(S) WHICH MAY RELEASE EDUCATION RECORDS -

University Official(s)/ Office(s):

\section{DESCRIPTION OF THE EDUCATION RECORDS WHICH MAY BE DISCLOSED -}

\section{RECIPIENT OF EDUCATION RECORDS -}

Person/Entity Receiving Records:

Address1:

Address2:

City, State:

Zip:

Phone:

Submit this Form to the Office Identified in Section 1 with Picture ID.

For WVU Use Only:

Received by

Type of Picture ID
Date

Rev. 2009-05-28- Legal - GF 
Table C4. Clinical Proficiency Evaluation Tool

\section{Introduction:}

Video starts with a title page entitled "Clinical Proficiency Evaluation"

Screen flips to a page entitled "Directions"

Words appear while male voice reads the directions out loud:

"You are about to begin the clinical proficiency evaluation. You will be shown a video clip. When the video is finished playing, you will be given a number of multiple choice questions to answer related to the video. You will have 15 seconds to answer each question. Please write your answers to each question on the answer sheet provided."

New screen, arrow pointing to circle in the lower part of the screen:

"In the lower right corner of the screen you will see a circle. When the circle is green, you still have time to answer the question. The circle will turn yellow, which indicates that you are nearing the end of the time allowed for that question. The circle will turn red, a referee whistle will be heard, and the next question will appear on the screen.

New screen. "Example"

Here is a sample video and question. Please do not put the answer to this question on your answer sheet. It is just an example problem."

Screen changes. Video shown of athlete grabbing his knee.

What part of the body has this athlete suffered an injury to?
A. Head
B. Stomach
C. Foot
D. Knee
E. Low Back
F. Elbow

In lower corner, circle goes from green to yellow, and to red. Whistle is heard.

New screen, with words appearing and male voice reading out loud:

"You are about to begin the clinical proficiency evaluation. Follow the directions for each question, and choose the best answers to put on your answer sheet. If you don't feel comfortable taking this examination or answering questions, you may stop at any time. Thank you for your time.

(NOTE: Time circles will appear on each question, and whistle will be heard as question changes) 
A video of a football player suffering from a head-on direct hit is seen. Video flashes to the first question.

1. You are signaled out onto the field by the officials. Which of the following steps should you perform immediately? (Choose all that apply)

a. Check airway, breathing, circulation

b. Call the athlete's parents to the field

c. Stabilize the athlete's head

d. Activate EMS

e. Remove the athlete's helmet

f. Let the athlete get up on their own to see how he feels

i. A, C

2. The athlete on the field is experiencing spinal cord shock. What should you do? (Choose all that apply)

a. Remove the helmet

b. Remove the facemask

c. Stretch the athlete's low back

d. Activate EMS

e. Spineboard the athlete

f. Check the athlete's dorsal pedal pulse

i. B, D, E

3. The athlete is able to get up and walk off the field to the sidelines without assistance. Based on this information, what would you do next? (Choose all that apply)

a. Ask the athlete if he knows where he is, the date, and the name of his coach

b. Give the athlete aspirin for a headache

c. Palpate the athlete's left upper trapezius muscle

d. Elevate the athlete's feet

e. Tell the coach the athlete is not to return to the game

f. Palpate the athlete's cervical area

i. A, C, E, F

4. Your athletic training staff has escorted the athlete to the athletic training room. You meet the athlete there and reassess his injury. Which of the following actions would you perform? (Choose all that apply)

a. Perform an Adson's test

b. Manually muscle test the deltoids

c. Check the deep tendon reflex of the triceps bilaterally

d. Give the athlete oxygen through a mask

e. Record the athlete's vital signs every 5 minutes

f. Check the active ROM of the athlete's neck

i. $\mathrm{B}, \mathrm{C}, \mathrm{F}$

5. To determine if the athlete has an upper motor neuron lesion, which of the following special tests should be performed? (Choose best answer) 

a. Kernig
b. Milgram
c. Oppenheim
d. Babinksi
e. Hoover
f. Phalen

i. $\mathrm{C}$

6. After re-evaluation, the athlete appears to have a first-degree concussion and a left-sided "burner." Which of the following steps would you perform? (Choose all that apply)

a. See if the athlete can perform push-ups

b. Put an ice pack on the athlete's left shoulder

c. Monitor the athlete for the next few days for any changes in condition

d. Give the athlete a soft neck collar to wear

e. Assess if the athlete still has sensory changes in his left upper arm or hand

f. Give the athlete shoulder strengthening exercises

$$
\text { i. } \mathrm{C}, \mathrm{E}
$$

7. The athlete has been doing shoulder rehab for his burner that includes working out on an upper body ergometer (UBE) since he is also not able to do any hitting drills. As you check to see how he's doing, you observe him slumping in his chair. When you ask him if he is all right, he responds slowly, and his speech appears to be slurred. You know this athlete is a Type I diabetic. How would you begin to evaluate his condition? (Choose all that apply)
a. Take the athlete's pulse
b. Ask the athlete when he last injected himself with insulin
c. Perform a cranial nerve assessment
d. Check for fruity smelling breath
e. Ask the athlete if he is having a hard time breathing
f. Observe for diaphoresis

$$
\text { i. } \mathrm{A}, \mathrm{B}, \mathrm{D}, \mathrm{F}
$$

8. You determine the athlete is suffering from insulin shock. What would be your next step in treating this athlete? (Choose all that apply)
a. Give the athlete a drink with high levels of sugar
b. Have the athlete eat a protein bar
c. Administer short-acting insulin
d. Lie the athlete supine and elevate his feet
e. Monitor vital signs
f. Keep the athlete warm with a blanket

i. A, E

9. A full football uniform prevents sweat evaporation from more than what percent of the body? (Choose the best answer)
a. $8 \%$
b. $27 \%$
c. $45 \%$ 
d. $60 \%$

e. $75 \%$

f. $90 \%$

i. D

10. When fitting shoulder pads for a football player, the epaulets should cover what? (Choose the best answer)
a. AC Joint
b. Sternum
c. Deltoid muscle
d. Biceps muscle
e. Trapezius muscle
f. Glenohumeral joint

i. C

A video of a soccer player who gets hit by another player in the stomach is seen. Video flashes to the next question.

11. As you approach the athlete, he is curled up in pain on the ground. What steps would you complete in your initial evaluation (Choose all that apply)

a. Ask where the pain is located

b. Ask if there is radiating pain

c. Listen to the athlete's heart

d. Palpate the athlete's abdominal area

e. Have an athletic training student bring out a stretcher

f. Have the athlete stand and jog around

$$
\text { i. A, B, D }
$$

12. After your initial evaluation, you have determined that this athlete has sustained a contusion to his lower right quadrant. At this time, what would you do? (Choose all that apply)

a. Position the athlete in a supine position with his knees bent

b. Monitor the athlete for any changes in pain intensity

c. Massage the athlete's abdominal area

d. Apply an ice pack to the injured area

e. Apply a neoprene rib belt

f. Assist the athlete to walk off the field if he is able to do so

i. A, B, D, F

13. You follow up with the athlete the next day in the athletic training room. He is sore, but in less pain today. How would you treat the athlete at this time? (Choose all that apply)

a. Continue to apply ice to the injured area

b. Begin to apply moist heat packs

c. Manually muscle test the abdominal muscles

d. Pad the area for activity

e. Have the athlete begin exercises on an upper body ergometer (UBE) 
f. Have the athlete drink a glass of Gatorade

i. A, D, E

14. You are traveling on the road with your school's women's tennis team, when one of your athletes comes to you with complaints of abdominal cramping and intermittent diarrhea for the past 2 days. How would you proceed with your assessment? (Choose all that apply)

a. Ask the athlete if she is nervous

b. Ask the athlete if they had this problem before

c. Ask the athlete what her diet has consisted of for the past 2-3 days

d. Check the athlete's blood pressure

e. Check the athlete's body fat levels

f. Palpate the athlete's abdomen

i. $\mathrm{A}, \mathrm{B}, \mathrm{C}$

15. Pain felt in this region indicates reason for immediate concern especially if the pain is non-traumatic in nature. (Select the correct region) (Video shows picture of abdomen, with marker over McBurney's point on the lower right abdomen as well as multiple other places)

a. Region 1

b. Region 2

c. Region 3

d. Region 4

e. Region 5

f. Region 6

i. Region 3

A video of a gymnastics athlete who goes down grabbing her right lower leg is seen. Video flashes to the next question.

16. How will you begin your initial evaluation of this athlete's condition? (Choose all that apply)

a. Immediately immobilize the lower right leg

b. Elevate the right lower leg

c. Palpate the leg for deformity

d. Observe the leg for edema or bleeding

e. Ask the athlete if she heard a snap

f. Ask the athlete what happened

i. C, D, E, F

17. You have ruled out a compound fracture for this gymnast, but suspect a fracture of both the tibia and fibula. With this information, how would you proceed at this time? (Choose all that apply)

a. Try to reduce the obvious deformity to get good alignment

b. Remove the athlete from the mat to apply an immobilizer

c. Pack the right leg in ice 
d. Check pulses in the ankle and foot

e. Check for Volkmann's contracture

f. Position the athlete in a supine position

i. C, D, E

18. You have activated EMS, and the athlete is about to be transported to the local emergency room. What do you do before the athlete leaves with the EMS team? (Choose all that apply)

a. Have the athlete walk to the ambulance with crutches

b. Have the coach follow the athlete to the hospital

c. Call ahead to the emergency room to make arrangements for her arrival

d. Check the athlete for signs of shock

e. Fill out an injury report

f. Assure the athlete she will be taken care of before she departs

i. D, E, F

Video of a tennis player who player runs to the net for a volley, stops and sets for the shot, and suddenly falls to the court while grabbing her left lower leg in severe pain. Video flashes to the next question.

19. After seeing the injury occur, how will you begin your initial evaluation of this injury? (Choose all that apply)

a. Ask the athlete to walk off the court

b. Check the athlete's leg for bleeding

c. Ask the athlete where the pain is located

d. Observe the lower extremity for deformity

e. Have an athletic training student apply an ice bag to her leg

f. Ask the athlete if she has ever injured her right leg before

i. C, D

20. You assist the athlete off the court and have her sit on a bench. What actions would you perform at this time? (Choose all that apply)

a. Palpate the calf for pain, swelling, or deformity

b. Perform a Thomas test bilaterally

c. Perform a Thompson's test bilaterally

d. Perform an anterior drawer test bilaterally on both ankles

e. Manually muscle test the ankle plantar flexors bilaterally

f. Check active range of motion of both ankles

i. A, C, E, F

21. Based on your initial assessment, you determine the athlete has a torn gastrocnemius muscle. The athlete is transported to the athletic training room in a golf cart. What would your initial treatment consist of during week 1? (Choose all that apply)

a. Begin gentle active range of motion exercises for the right ankle

b. Applying ice packs to the lower leg

c. Applying a compression wrap 
d. High volt galvanic stimulation

e. Calf raises

f. Fitting the athlete with crutches

i. $\mathrm{B}, \mathrm{C}, \mathrm{D}, \mathrm{F}$

22. It has been determined that this athlete needs crutches initially. Which description best dictates the correct fitting posture? (Choose the correct answer)

a. Elbows at 20 degrees, 3-4 fingers between axilla and pad, 6" out, 6" up from feet

b. Elbows at 30 degrees, 2-3 fingers between axilla and pad, 12" out, 4" up from feet

c. Guess how tall the athlete is and find crutches to match his height

d. Elbows at 20 degrees, 2-3 fingers between axilla and pad, 8" out, 2" up from feet

e. Elbows at 30 degrees, 3-4 fingers between axilla and pad, and crutches held out at a comfortable distance

f. Elbows at 30 degrees, 2-3 fingers between axilla and pad, 6" out, 2" up from feet i. $\mathrm{F}$

23. Four weeks have passed since the initial injury. The athlete has minimal to no discomfort with active plantar flexion, but the movement is still weak against resistance (4/5). All other ankle and knee motions are within normal ranges. Which of the following exercises would be appropriate? (Choose all that apply)
a. Stationary bike
b. Push-ups
c. Proprioception exercises
d. Calf raises
e. Progressive-resistance quadriceps exercises
f. Plyometric exercises

i. A, C, D, E

24. Six weeks have passed since the initial injury. The athlete has done very well during her rehabilitation. What specific criteria would you use to determine that this athlete is fully recovered and ready to participate in tennis? (Choose all that apply)

a. The athlete has no complaints of lower extremity pain at rest or during activity

b. The athlete has no pain while performing a hamstring curl

c. The athlete can hop on the injured leg without pain

d. The athlete is getting bored with her rehabilitation program

e. The team physician clears the athlete to return to full activity

f. The coach demands the athlete's return to competition

i. A, B, C, E

Video shows a picture of a swollen ankle.

25. A rugby athlete comes to you acutely with an ankle that looks like this. What will your initial evaluation include? (Choose all that apply)

a. Check the athlete's hamstring flexibility

b. Observe both ankles for swelling/deformity

c. Gently bang on the heel of the injured ankle 
d. Perform a Lachman's test

e. Palpate the ankle and foot for areas of tenderness

f. Perform an anterior drawer test on both ankles

$$
\text { i. } \mathrm{B}, \mathrm{E}, \mathrm{F}
$$

26. You have completed your initial evaluation and suspect that the athlete has a seconddegree lateral ankle sprain. What is your initial treatment going to include? (Choose all that apply)

a. Keep the athlete in nonweightbearing

b. Call the team physician with your assessment

c. Begin RICE

d. Fit the athlete with crutches and horseshoe pad

e. Set up an appointment for an x-ray examination

f. Begin a Theraband stretching program for the ankle

i. A, C, D

27. What instructions will you give the athlete for home? (Choose all that apply)

a. If they have mild/moderate pain tonight, have them go to the emergency room

b. Begin lower extremity closed-chain exercises as tolerated

c. Keep ice packs on the ankle frequently and elevate it when the athlete is not ambulating

d. Keep a compression wrap on the ankle except when the athlete is sleeping

e. Have the athlete wear high-top sneakers

f. Have the athlete try to hop on the affected leg the next day to see if it still hurts

i. C, D

A video of a cross country race is seen. At the end of the race the athlete collapses. Video flashes to the next question.

28. As you approach the athlete, you notice he appears somewhat ashen in color and is looking confused. As you escort him to the medical tent, you notice his skin is cool and clammy to the touch. How will you begin your initial evaluation? (Choose all that apply)

a. Ask the athlete what medications he is taking

b. While maintaining the athlete's privacy with a light blanket/sheet, obtain a core temperature measurement

c. Take the athlete's blood pressure and pulse rate

d. Perform a cranial nerve check

e. Check the athlete's fingernails for good capillary refill

f. Ask the athlete's name, the date, and where they are right now

i. $\mathrm{A}, \mathrm{B}, \mathrm{C}, \mathrm{F}$

29. Based on your initial evaluation, you determine the athlete is experiencing an episode of heat exhaustion. How would you proceed in treating this athlete? (Choose all that apply)

a. Move the athlete to a cool area

b. Place the athlete in a supine position and elevate his feet

c. Continue to monitor vital signs

d. Restrict the athlete's fluid intake for at least 1-2 hours 
e. Cool the athlete by sponging or toweling him with cold water, by use of a fan, or by placing ice packs around the neck, axilla, or groin area

f. Give the athlete a massage to relax him

$$
\text { i. A, B, C, E }
$$

30. The women's swimming coach reports to your athletic training room to discuss the behavior of one of her athletes. After reviewing what the coach has observed over the past month, you both suspect the athlete may be showing signs of an eating disorder. How would you advise the coach to proceed? (Choose all that apply)

a. Confront the athlete with her problem and do not allow her to compete until the team physician evaluates her

b. Do not overemphasize the impact of lower body weight on the athlete's performance

c. Tell the coach to keep a diary of when the athlete eats

d. Have the coach encourage the athlete to maintain good nutritional habits to optimize her performance

e. Keep the athletic training staff informed if the athlete dramatically changes her behavior

f. Ignore the problem and hope it will go away over time

i. $\mathrm{B}, \mathrm{D}, \mathrm{E}$

31. The athlete has talked with the coach and comes to your office to express her fear of being cut from the team. With the information available, how would you proceed? (Choose all that apply)

a. Assist the athlete in setting practical goals pertaining to safe means of dieting and determining a sensible target weight

b. Use scare tactics to discourage the use of laxatives and diuretics

c. Address the issue with your athletic director

d. Tell the athlete she has nothing to worry about and you will talk to the coach for her

e. Tell the athlete she should think about getting professional counseling to overcome her problem

f. Set up a meeting between the coach, athlete, and yourself to discuss what has been observed and how it will be managed

i. A, F

32. The athlete concedes to the coach and the athletic trainer that she may have an eating disorder. With this information, what are the next steps? (Choose all that apply)

a. Call the team physician

b. Set up an appointment with a psychologist

c. Weigh the athlete on a daily basis

d. Arrange for the athlete to be hospitalized for a week to force feed her

e. Arrange counseling meetings for the athlete with a sports nutritionist

f. Put the athlete on a diet consisting of Ensure, bananas, and red meat at least twice a day.

i. A, B 
33. A wrestler comes to the athletic training room during his off season and asks you for help losing 15 pounds. How would you advise the wrestler in his initial steps to lose weight safely? (Choose all that apply)

a. Measure the athlete's percent body fat using calipers

b. Have the athlete keep a log of what he eats on a daily basis

c. Monitor the athlete's weight loss progress once a week

d. Put the athlete on a fasting diet for two days

e. Make sure the athlete drinks eight glasses of water daily

f. Have the athlete wear a rubber suit while running

i. $\mathrm{A}, \mathrm{B}, \mathrm{C}, \mathrm{E}$

34. The athlete successfully loses the weight. How would you advise the athlete in maintaining his current weight? (Choose all that apply)

a. Have the coach monitor the athletes food intake

b. Have the athlete drink eight glasses of water a day

c. Have the athlete double his exercise session in duration

d. Have the athlete take laxatives

e. Refer the athlete to a sports nutritionist

f. Encourage the athlete to eat four to six small balanced meals a day

i. $\mathrm{B}, \mathrm{F}$

35. A football player comes to you requesting help in improving his general lower body strength and overall conditioning. What suggestions would you make to assist this athlete in a preseason training program? (Choose all that apply)

a. Instruct the athlete in a general flexibility program

b. Have the athlete run up and down the stadium stairs in pads

c. Monitor the athlete's respiratory rate while at rest

d. Make the exercises sports-specific

e. Have the athlete participate in other sports

f. Put the athlete on a red meat and legume diet

i. A, D

36. As the football season begins, the athlete continues to seek your advice to keep him fit and healthy. What types of things might you emphasize to keep him in condition during the season? (Choose all that apply)

a. Have the athlete run 2 miles three times a week

b. Continue strength training exercises for the lower body

c. Make sure the athlete takes 2 to 3 days off a week so he gets rest

d. Establish a maintenance-conditioning program to be performed on a regular basis

e. Put the athlete on a clear liquid diet

f. Monitor the athlete's blood pressure on a daily basis

i. A, B, D 
37. After seeing this occur, you immediately report to the victim. He is conscious and states that he is nauseous, and he sweating profusely. He also tells you that he has "a heavy pressure in his chest." How will you begin your initial evaluation of the athlete's condition? (Choose all that apply)

a. Ask the victim what happened

b. Check the victim's vital signs

c. Ask the victim if they are taking any medications

d. Ask the victim if they have experienced this before

e. Ask if they have pain going down the left arm

f. Administer nitroglycerine

$$
\text { i. A, B, C, D, E }
$$

38. Based on the above information, you suspect the individual might be having a myocardial infarction. How will you proceed? (Choose all that apply)

a. Send someone for the AED

b. Lie the victim on their back

c. Put ice on the back of their neck

d. Ask if they are short of breath

e. Activate EMS

f. Try to put the victim at ease; speak to them with confidence, and let them know what you are doing to keep them calm.

$$
\text { i. A, D, E, F }
$$

39. You are covering a soccer game on a cold day when you notice one of your players is having a hard time breathing about 7 minutes into the game. He comes off the field coughing and complaining of "chest tightness." How will you begin your initial evaluation of this player's condition? (Choose all that apply)

a. Ask if the athlete is diabetic

b. Ask the athlete if this has ever happened before

c. Give the athlete Immodium

d. Lie the athlete in a supine position, and flex his knees to his chest

e. Ask the athlete if he has an inhaler

f. Tell the coach you are going to send the athlete to the team physician i. B, E

40. You suspect that the athlete has EIB. What would be your next step in caring for this athlete? (Choose all that apply)

a. Have the athlete breathe slowly through their nose

b. Check the athlete's pulse

c. Have the athlete take two puffs of a short-acting inhaler

d. Give the athlete a warm drink like hot tea

e. Tell the coach you are taking the athlete out of the game

f. Monitor the athlete's symptoms until they subside and continue to monitor the athlete for up to 12 hours after exercise. 


\section{i. A, E, F}

A video of a basketball player who goes down grabbing his knee is seen. Video flashes to the next question.

41. The athlete is able to limp off the court unassisted. He reports that his knee bent sideways when he landed, and he felt a sharp pain. He cannot recall feeling a pop or snap. What actions would you take during your initial assessment? (Choose all that apply)

a. Ask the athlete to point to where he feels pain

b. Apply a knee immobilizer to the injured extremity

c. Have the athlete perform 10 calf raises

d. Manually muscle test the strength of the hip flexors bilaterally

e. Check the athlete's papillary reaction

f. Palpate the knee's anterolateral/anteromedial joint line

$$
\text { i. A, D, F }
$$

42. What special tests would you perform during your evaluation of this injury? (Choose all that apply)

a. Lachman's test bilaterally

b. Tinel's test bilaterally

c. Valgus test bilaterally

d. Posterior drawer test bilaterally

e. McMurray's test bilaterally

f. Patellar apprehension test bilaterally

i. A, C, D, E, F

43. After being examined by the team physician, the athlete is diagnosed with a seconddegree medial collateral sprain. What actions would you take to control the pain and swelling and address the limitations in range of motion? (Choose all that apply)

a. Apply moist heat packs to the knee

b. Have the athlete use a rowing machine

c. Fit the athlete with crutches

d. Begin isotonic hamstring strength exercises

e. Give the athlete Tylenol with codeine for pain

f. Use high-volt galvanic stimulation

i. $\mathrm{C}, \mathrm{F}$

44. The team physician recommends the athlete begin rehabilitation in one week. Knowing the athlete will be unable to return to basketball for about 4-5 weeks, how would you go about beginning a functional exercise program and maintaining his aerobic condition during 1-2 weeks post-injury? (Choose all that apply)

a. Swimming (regular crawl)

b. Running on treadmill

c. Stairmaster (low resistance)

d. Upper body ergometer

e. Fartlek training 


\section{f. Stationary biking}

$$
\text { i. A, C, D, F }
$$

A video of a bike crash is seen. Video flashes to the next question.

45. Which biker would you tend to first? (Choose the best answer)

a. A conscious athlete who is laying absolutely motionless complaining of neck pain

b. An unconscious athlete who is bleeding profusely from his arm

c. A conscious athlete who is screaming in pain and grabbing his knee

d. A conscious athlete who appears to be going into shock

e. A conscious athlete who is screaming at another biker about ripped biking shorts

f. A conscious athlete whose elbow is dislocated

i. B

46. One of the bikers is complaining of severe low back pain that is radiating down his right leg. He is very guarded and is slightly forward flexed at the waist. The athlete reports significant increasing pain down his leg to the level of his foot when he tries to bend forward. You suspect the athlete has a lumbar herniated nucleus pulposis. Which steps would you take at this time to treat this athlete? (Choose all that apply)

a. Have the athlete lie prone

b. Teach the athlete a series of Williams' Flexion exercises

c. Tape the athlete's lower back for support and send them back into the bike race

d. Give the athlete a muscle relaxant like Flexeril

e. Send the athlete to a chiropractor

f. Place an ice pack on the athlete's back after the race

$$
\text { i. A, F }
$$

47. One of the athletes in the crash was hit hard in the left upper abdominal quadrant. As you run to him, you discover that he is going into shock and is vomiting. The athlete is also complaining of left arm and shoulder pain. What is your impression of this injury? (Choose the best answer)

a. Ruptured spleen

b. Left shoulder subluxation

c. Appendicitis

d. Abdominal contusion

e. Bladder rupture

f. Intestinal rupture

i. A

48. One of the bikers has a deep laceration above the left eyebrow from being elbowed in the collision. What are your next steps? (Choose all that apply)

a. Check the pupil for reflex movements with a penlight

b. Rinse the wound with saline solution

c. Apply ice to the injury

d. Use steri-strips to close the laceration

e. Apply compression directly to the eye once you have "closed" the laceration 
f. Apply antiseptic ointment to the laceration

i. $\mathrm{A}, \mathrm{B}, \mathrm{C}, \mathrm{D}$

49. A male biker sustained a direct blow to the genital area. What can you do to immediately decrease the pain? (Choose the best answer)

a. Use an ice pack to the area with the athlete in a supine position, knees in extension.

b. Use direct pressure on the testes

c. Have the athlete lie supine with his knees bent to his chest to decrease the strain on the scrotum and apply ice to the affected area

d. Have the athlete lie on his side with his knees extended

e. Place a moist heat pack over the area

f. Have the athlete jump up and down

i. $\mathrm{C}$

50. One of the bikers is having a seizure. Which of the following measures are appropriate steps in the athlete's management? (Choose all that apply)

a. Keep spectators out of the way

b. Protect the patient's head and body from injury

c. Turn the patient on his or her side

d. If the athlete is in status epilepticus or it is a first seizure, immediately seek additional medical support

e. Try to keep the athlete's mouth open by any means to prevent airway obstruction

f. Call the athlete's next of kin to inform him or her of the problem and the care given

i. A, B, C, D 


\section{APPENDIX D}

\section{ADDITIONAL RESULTS}

Table D1. Descriptive Statistics- Clinical Evaluation

\begin{tabular}{lll} 
& Mean and Standard Deviation & Range \\
\hline GPA & $3.40 \pm .330$ & 1.17 \\
Clinical Evaluation: Sophomore & $.902 \pm .031$ & .10 \\
Clinical Evaluation: Junior & $.927 \pm .045$ & .16 \\
Clinical Evaluation: Senior & $.914 \pm .057$ & .19 \\
Clinical Proficiencies & $.882 \pm .030$ & .10 \\
Clinical Proficiency Evaluation Tool & $.631 \pm .058$ & .24 \\
\hline
\end{tabular}


Table D2. Clinical Evaluation Correlations

$\begin{array}{llllll}\text { GPA } & \begin{array}{l}\text { Clinical } \\ \text { Evaluation: } \\ \text { Sophomore }\end{array} & \begin{array}{l}\text { Clinical } \\ \text { Evaluation: } \\ \text { Junior }\end{array} & \begin{array}{l}\text { Clinical } \\ \text { Evaluation: } \\ \text { Senior }\end{array} & \begin{array}{l}\text { Clinical } \\ \text { Proficiencies }\end{array} & \begin{array}{l}\text { Clinical } \\ \text { Proficiency } \\ \text { Evaluation } \\ \text { Tool }\end{array} \\ \mathrm{r}=1 & \mathrm{r}=.234 & \mathrm{r}=.639 & \mathrm{r}=-.256 & \mathrm{r}=.711 & \mathrm{r}=.554 \\ & \mathrm{p}=.402 & \mathrm{p}=.010 & \mathrm{p}=.357 & \mathrm{p}=.003 & \mathrm{p}=.032 \\ \mathrm{r}=.234 & \mathrm{r}=1 & \mathrm{r}=-.267 & \mathrm{r}=-.201 & \mathrm{r}=.000 & \mathrm{r}=.205 \\ \mathrm{p}=.402 & & \mathrm{p}=.337 & \mathrm{p}=.473 & \mathrm{p}=.998 & \mathrm{p}=.463\end{array}$

Evaluation:

Sophomore

Clinical

$$
\mathrm{r}=.639
$$

$\mathrm{r}=-.267$

$\mathrm{r}=1$

$\mathrm{r}=.228$

$\mathrm{r}=.754$

$\mathrm{r}=.265$

Evaluation:

$\mathrm{p}=.010 \quad \mathrm{p}=.337$

$\mathrm{p}=.413$

$\mathrm{p}=.001$

$\mathrm{p}=.340$

Junior

Clinical

$r=-.256 \quad r=-.201$

$\mathrm{r}=.228$

$\mathrm{r}=1$

$\mathrm{r}=.046$

$\mathrm{r}=-.013$

Evaluation:

$\mathrm{p}=.357 \quad \mathrm{p}=.473$

$\mathrm{p}=.413$

$\mathrm{p}=.871$

$\mathrm{p}=.964$

Senior

Clinical

$$
\mathrm{r}=.711 \quad \mathrm{r}=.000
$$

$\mathrm{r}=.754$

$\mathrm{r}=.046$

$\mathrm{r}=1$

$\mathrm{r}=.329$

Proficiencies

$\mathrm{p}=.003$

$\mathrm{p}=.998$

$\mathrm{p}=.001$

$\mathrm{p}=.871$

$\mathrm{p}=.231$

Clinical

$\mathrm{r}=.554 \quad \mathrm{r}=.205$

Proficiency

$\mathrm{p}=.032$

$\mathrm{p}=.463$

$\mathrm{r}=.265$

$\mathrm{r}=-.013$

$\mathrm{r}=.329$

$\mathrm{r}=1$

Evaluation

$\mathrm{p}=.340$

$\mathrm{p}=.964$

$\mathrm{p}=.231$

Tool 


\section{APPENDIX E \\ RECOMMENDATIONS FOR FUTURE RESEARCH}

1. A recommendation for future research is to repeat this study using a larger sample size.

2. Another recommendation for future research is to repeat this study using a larger number of undergraduate athletic training programs across the nation.

3. Another recommendation would be to use athletic training GPAs instead of overall GPAs in data collection.

4. Another standardized method of grading the clinical evaluation proficiency tool should also be used such as a scan-tron format that automatically grades the exams.

5. More insight as to what should be included in the clinical proficiency evaluation tool may also help in yielding better results.

6. Conduct a modified Delphi technique study of all CAATE athletic training entry-level program directors asking them to determine which clinical proficiencies should be included on a clinical proficiency evaluation tool. After obtaining responses develop the clinical proficiency evaluation tool that may be able to be generalized to other CAATE athletic training education programs than the one developed in this study.

7. It may also be helpful to give the examination tool to athletic training students in their junior year, and then compare those scores to the same test given their senior year to determine if the students are, in fact, maintaining the knowledge base over time. 


\section{ADDITIONAL REFERENCES}

11. Weidner TG, Henning JM. Importance and applicability of approved clinical instructor standards and criteria to certified athletic trainers in different clinical education settings. $J$ Athl Train. 2005;40(4):326-332.

12. Lauber CA, Toth PE, Leary PA, Martin D, Killian CB. Program directors' and clinical instructors' perceptions of important clinical-instructor behavior categories in the delivery of athletic training clinical instruction. J Athl Train. 2003;38(4):336-341.

13. Weidner TG, Henning JM. Development of standards and criteria for the selection, training, and evaluation of athletic training approved clinical instructors. $J$ Athl Train. 2004;39(4):335-343.

14. Mensch JM. Are we asking too much for athletic training students in the clinical setting? Athl Ther Today. 2006;14(2):30-31.

15. Miller MG, Berry DC. An assessment of athletic training students' clinical-placement hours. J Athl Train. 2002;37(4 Supplement):S-229-S-235.

16. Board of Certification for the Athletic Trainer. Available at: http://www.bocatc.org/index.php?option=com_content\&task=view\&id=37\&Itemid=39. Accessed October 2, 2009.

17. Laurent T, Weidner TG. Clinical instructors; and student athletic trainers' perceptions of helpful clinical instructor characteristics. J Athl Train. 2001;36(1):58-61.

18. Weidner TG, Noble GL, Pipkin JB. Athletic training students in the college/university setting and the scope of clinical education. J Athl Train. 2006;41(4):422-426.

19. Weidner TG, Laurent T. Selection and evaluation guidelines for clinical education settings in athletic training. J Athl Train. 2001;36(1):62-67.

20. Delforge GD, Behnke RS. The history and evolution of athletic training education in the United States. J Athl Train. 1999;34(1):53-61.

21. Heinerichs S, Curtis N. Instructional strategy for clinical education: the 3-2-1 technique. Athl Ther Today. 2006;14(4):52-53.

22. Kelly SP. The exemplary clinical instructor: a qualitative case study. J Phys Ther Edu. 2007;21(1):63-69.

23. Weidner TG, Popp JK. Peer-assisted learning and orthopedic evaluation psychomotor skills. J Athl Train. 2007;42(1):143-149. 
24. Jarski RW, Kulig K, Olson RE. Clinical teaching in physical therapy: student and teacher perceptions. Phys Ther. 1990;70(3):173-178.

25. Berry DC, Miller MG, Berry LM. Effects of clinical field-experience setting on athletic training students' perceived percentage of time spent on active learning. J Athl Train. 2004;39(2):176-184.

26. Wojciechowski M. Clinical instructor education and credentialing program: a decade later. PT: Magazine of Physical Therapy. Feb2007;15(2):70-4.

27. Geisler PR. Multiculturalism and athletic training education: implications for educational and professional progress. J Athl Train. 2003;38(2):141-151.

28. Amato HK, Konin JG, Brader H. A model for learning over time: the big picture. J Athl Train. 2002;37(2 Supplement):S-236-S-240.

29. Coker CA. Consistency of learning styles of undergraduate athletic training students in the traditional classroom versus the clinical setting. J Athl Train. 2000;35(4):441444.

30. Foster DT, Leslie DK. Clinical teaching roles of athletic trainers. J Athl Train. 1992;27(4):298-302.

31. Fuller D. Critical thinking in undergraduate athletic training education. J Athl Train. 1997;32(3):242-213.

32. Heinrichs KI. Problem-based learning in entry-level athletic training professionaleducation programs: A model for developing critical-thinking and decision-making skills. J Athl Train. 2002;37(4 Supplement): S-189-S-198.

33. Konin JG, Amato HK, Brader H. Incorporating the renne test into the learning-over-time model. Athl Ther Today. 2002;7(5):15-17.

34. Leaver-Dunn D, Harrelson GL, Martin M, Wyatt T. Critical-thinking predisposition among undergraduate athletic training students. J Athl Train. 2002;37(4 Supplement): S143-S-151.

35. Peer KS, Rakich JS. Accreditation and continuous quality improvement in athletic training education. J Athl Train. 2000;35(2):188-193.

36. Rich VJ. Clinical instructors' and athletic training students' perceptions of teachable moments in an athletic training clinical education setting. J Athl Train. 2009;44(3):294303.

37. Starkey C. Reforming athletic training education. J Athl Train. 1997;32(2)143-144. 
38. Walker SE. Active learning strategies to promote critical thinking. J Athl Train. 2003;38(3):263-267.

39. Pircher, CM. Perceived Preparedness of Graduate Assistant Novice Approved Clinical Instructors for Supervision of Undergraduate Athletic Training Students. [master's thesis]. Morgantown, WV: West Virginia University; 2008.

40. Mathies AL, Denegar CR, Arnhold RW. Changes in athletic training education as a result of changing from NATA-PEC to CAAHEP. J Athl Train. 1995;30(2):159-132.

41. Commission on Accreditation of Athletic Training Education. 38. http://caate.net/documents/standards.15.7.2007.pdf. Accessed October 27, 2009.

42. Curtis N, Helion JG, Domsohn M. Student athletic trainer perceptions of clinical supervisor behaviors: A critical incident study. J Athl Train. 1998;33(3):249-253.

43. Meyer LP. Athletic training clinical instructors as situational leaders. J Athl Train. 2002;37(4 Supplement): S-261-S-265.

44. Knight, KL. Educational perceptions vs. reality; classroom and clinical education. Ath Train Edu J. 2006;1(Apr-Dec):15-17.

45. National Athletic Trainers' Association Board of Certification. Role Delineation Study. 5th ed. Omaha, Neb: NATABOC, Inc; 2004.

46. Board of Certification Inc. Athletic Trainer Credentialing Candidate Handbook. Updated November 18, 2009. Accessed November 19, 2009.

47. National Athletic Trainers Association Certified Athletic Trainers Exam Details. Accessed November 19, 2009. www.test-preparation.ca/personal-trainer/nata.htm.

48. Van Ost, L., Manfre, K. and Lew, K.M.(2006) Athletic Training Exam Review: A Student Guide to Success, Third Edition. Slack Publishing, Thorofare, NJ(June, 2006) 